This is a non-peer reviewed preprint submitted to EarthArXiv.

1 This is a non-peer reviewed preprint submitted to EarthArXiv. This manuscript has been

2 submitted to Earth, Planets and Space.

3

4 Title: Co- and postseismic slip behaviors extracted from decadal seafloor geodesy

5 after the 2011 Tohoku-oki earthquake

6 Author \#1: Shun-ichi Watanabe, Hydrographic and Oceanographic Department, Japan

7 Coast Guard, 3-1-1, Kasumigaseki, Chiyoda-ku, Tokyo, 100-8932, Japan, s-

$8 \quad$ watanabe@jodc.go.jp

9 Author \#2: Tadashi Ishikawa, Hydrographic and Oceanographic Department, Japan

10 Coast Guard, 3-1-1, Kasumigaseki, Chiyoda-ku, Tokyo, 100-8932, Japan,

11 ishikawa@jodc.go.jp

12 Author \#3: Yuto Nakamura, Hydrographic and Oceanographic Department, Japan Coast

13 Guard, 3-1-1, Kasumigaseki, Chiyoda-ku, Tokyo, 100-8932, Japan,

14 ynakamura@jodc.go.jp

15 Author \#4: Yusuke Yokota, Institute of Industrial Science, University of Tokyo; 4-6-1,

16 Komaba, Meguro-ku, Tokyo, 153-8505, Japan, yyokota@iis.u-tokyo.ac.jp

17 Corresponding author \#1 
This is a non-peer reviewed preprint submitted to EarthArXiv.

\section{Abstract}

19 Investigations of the co- and postseismic processes of the 2011 Tohoku-oki earthquake

20 provide essential information on the seismic cycle in the Japan Trench. Although

21 various postseismic models have been proposed, no consensus has been reached,

22 especially on the along-strike extensions of the main rupture due to the lack of

23 conclusive evidence, even in the coseismic process. To decompose the postseismic

24 transient processes in and around the source region, i.e., viscoelastic relaxation and

25 afterslip, long-term postseismic geodetic observation on the seafloor plays an essential

26 role. Here, from decadal seafloor geodetic data, we provide empirical evidence for

27 offshore aseismic afterslip on the rupture edges that had almost decayed within 2-3

28 year. The afterslip regions are considered to have stopped the north-south rupture

29 propagation. In the southern source region $\left(\sim 37^{\circ} \mathrm{N}\right)$, despite not resolved by coseismic

30 geodetic data, shallow tsunamigenic slip near the trench is captured by postseismic

31 seafloor geodesy as a subsequent viscoelastic deformation causing persistent seafloor

32 subsidence at a geodetic site off-Fukushima. After a decade from the earthquake, the 
This is a non-peer reviewed preprint submitted to EarthArXiv.

33 long-term viscoelastic relaxation process is currently in progress and is still dominant in

34 the rupture area.

35

36 Keywords

372011 Tohoku-oki earthquake; GNSS-A; seafloor geodesy; Postseismic crustal

38 deformation; Shallow tsunamigenic slip; Afterslip; Viscoelastic relaxation

39

40 Main Text

$41 \quad 1$ Introduction

42

In general, a large fault rupture is followed by postseismic relaxation processes

43 such as viscoelastic relaxation in the asthenosphere and aseismic slip on the fault plane,

44 which lead to transient crustal deformation on the solid Earth's surface (e.g., Wang et

45 al., 2012). Postseismic geodetic data following a megathrust earthquake show the sum

46 of these relaxation processes and interplate backslip due to the secular plate subduction.

47 Along the Japan Trench, postseismic processes were triggered by the 2011 Tohoku-oki

48 earthquake $\left(M_{\mathrm{w}} 9.0\right)$ and continue in this decade. Clarifying the interplate slip behaviors 
This is a non-peer reviewed preprint submitted to EarthArXiv.

49 for the co- and postseisimic phase will contribute to the understanding of the frictional

50 state of faults, slow earthquake activities, and seismic cycles in this region.

51 The Tohoku-oki earthquake caused trench-ward seafloor displacements of

52 several tens of meters (Sato et al., 2011; Kido et al., 2011), reaching about $50 \mathrm{~m}$ at the

53 trench (Fujiwara et al., 2011). Using seafloor geodetic data (Sato et al., 2011; Kido et

54 al., 2011), which provided definitive evidence for a coseismic slip, an extremely large

55 slip was estimated at the plate interface shallower than the hypocenter (Figure 1)

56 (Ozawa et al., 2012; Iinuma et al., 2012; Sun et al., 2017; Wang et al., 2018). Except for

57 the north-south spread of shallow rupture, where the geodetic data at that time could not

58 resolve the slips, a consensus has been reached on the north-south rupture propagation

59 at depths near the hypocenter; almost all fault models produce similar results as

60 summarized by Sun et al. (2017) and Wang et al. (2018). This implies that the rupture in

612011 did not progress to the northern region $\left(>39^{\circ} \mathrm{N}\right)$, even though $M_{\mathrm{w}} 8$ earthquakes

62 have historically occurred in this region (Figure 1) (Nagai et al., 2001; Yamanaka and

63 Kikuchi, 2004). Investigations of the postseismic behaviors, including the occurrence of

64 afterslip, in the northern and southern regions outside the main rupture area provide 
This is a non-peer reviewed preprint submitted to EarthArXiv.

essential information on how rupture propagation was restrained in a compact region in

66 the depths near the hypocenter. For the detection of transient postseismic crustal deformation to decompose the

68 elementary processes, sufficiently long-term, high-frequency, and well-distributed

69 geodetic data are required because these sources have different decay times and

70 deformation patterns (e.g., Wang et al., 2012). Although the terrestrial Global

71 Navigation Satellite System (GNSS) observation network has extremely high

72 spatiotemporal resolution, it cannot easily decompose the transient processes because

73 the two processes of interest cause similar trench-ward movements in the onshore

74 regions and thus cannot be distinguished from one another. In contrast, the viscoelastic

75 and afterslip effects cause displacements in opposite directions on the seafloor above

76 the main rupture, i.e., the landward and trench-ward directions, respectively. Therefore,

77 seafloor geodetic observations can be used to decompose transient deformation sources

78 despite their lower temporal resolution compared to that of terrestrial observations.

79 Actually, seafloor geodetic technique detected postseismic landward movements larger

80 than the subduction rate $(\sim 9 \mathrm{~cm} /$ year) (Argus et al., 2011) above the main rupture area, 
This is a non-peer reviewed preprint submitted to EarthArXiv.

81 whereas terrestrial geodetic sites showed trench-ward movements. This is a conclusive

82 evidence for the dominance of viscoelastic relaxation in the main rupture area

83 (Watanabe et al., 2014; Sun et al. 2014; Tomita et al., 2017; Honsho et al., 2019).

84 The seafloor observation results stimulated researchers to develop postseismic

85 deformation models incorporating the viscoelastic effects. Table 1 summarizes the

86 postseismic models with (1) referencing the seafloor geodetic data, (2) incorporating the

87 afterslip dislocation models, (3) modeling the subducting cold slab, and (4) calculating

88 the viscoelastic deformation in wider area than a latitude range of $37-39^{\circ} \mathrm{N}$. Every

89 model indicated that the deformation patterns in the main rupture area can be roughly

90 explained as the viscoelastic response, but that the observed deformation in the outside

91 of main rupture cannot be reproduced only by viscoelastic relaxation. Some models put

92 additional afterslip patches in the offshore region to reproduce the geodetic data (e.g.,

93 Sun and Wang., 2015; Freed et al., 2017), even though these were only the tentative

94 models because of the insufficient spatiotemporal resolution and observation period (at

95 most 5 years) of available seafloor data. 
This is a non-peer reviewed preprint submitted to EarthArXiv.

97 for the postseismic deformation modeling. Many researchers had adopted coseismic slip

98 distribution model inverted from seafloor and terrestrial geodetic data with roughness

99 dumping (e.g., Iinuma et al., 2012; Freed et al., 2017), though the geodetic network in

1002011 did not cover the whole source region, for which there is thus no information

101 especially on coseismic rupture in the shallower portion. Tsunami data, which are

102 sensitive to topographical changes of the seafloor, indicate that the tsunamigenic area

103 was extended, especially in the northern $\left(>39^{\circ} \mathrm{N}\right)$ and southern $\left(\sim 37^{\circ} \mathrm{N}\right)$ areas along

104 the trench (Figure 1) (Satake et al., 2013). This feature did not appear in the geodetic

105 inversion due to the absence of data. Nonetheless, the difference in coseismic input

106 would affect the postseismic relaxation processes. For instance, a viscoelastic model

107 proposed by Agata et al. (2019), where an output of seismic cycle simulation (Nakata et

108 al., 2016) that included an additional shallow slip near the trench eastern off-Fukushima

$109\left(\sim 37^{\circ} \mathrm{N}\right)$ is applied to the coseismic input, suggested that viscoelastic relaxation can

110 cause significant seafloor deformation in the off-Fukushima region, whereas other

111 models based on the geodetic coseismic input could not induce enough stress to cause 
This is a non-peer reviewed preprint submitted to EarthArXiv.

112 significant viscoelastic deformation there (e.g., Sun et al., 2014; Freed et al., 2017). The

113 difference between models suggests that we will be able to estimate shallow coseismic

114 slip behavior and following postseismic models by decomposing and discussing the

115 postseismic deformation sources with longer-term seafloor geodetic data.

116 In this study, decadal seafloor geodetic data that contain the temporal evolutions

117 of surface velocity are used to decompose the deformation sources. Based on the results,

118 we clarify the co- and postseismic slip behaviors in the northern and southern parts of

119 the source region.

120

\section{Data and Methods}

121

To investigate the temporal evolution of seafloor crustal deformation, the Japan

122 Coast Guard (JCG) regularly performs seafloor geodetic observations using GNSS -

123 acoustic ranging combined seafloor positioning system (GNSS-A) (Additional file 1:

124 Figure S1), in the Japan Trench region (e.g., Watanabe et al., 2020). GNSS-A data were

125 obtained at six JCG sites (KAMN, KAMS, MYGI, MYGW, FUKU, and CHOS; Table

126 S1) from March 2011 to June 2020 using survey vessels, and were processed with

127 GARPOS v1.0.0 (Watanabe et al., 2021d). Note that the newer analysis method, which 
This is a non-peer reviewed preprint submitted to EarthArXiv.

128 incorporated the estimation process for spatially gradient sound speed structure, has

129 been applied to the previously published data (Watanabe et al., 2014). The JCG also

130 performed GNSS-A observations at five sites (G08, G10, G12, G14, and G17; Table

131 S1) installed by Tohoku University (TU) (Kido et al., 2015) since 2013, independently

132 of TU. We additionally reprocessed the GNSS-A data before the Tohoku-oki

133 earthquake at five JCG sites (Sato et al., 2013a) using the present analysis method to

134 determine the preseismic seafloor velocities.

All GNSS-A data used in this study are available at Zenodo (Watanabe et al.,

136 2021a;b). Note that the GNSS-A data before 2009 were obtained by drifting

137 observations (Additional file 1: Figure S1a), which are less precise than the recent

138 results obtained by sailing observations (Sato et al., 2013b; Ishikawa et al., 2020).

139 To extract the annual-scale velocity changes, we took the following steps: We

140 first subtract the effects of aftershocks that can cause coseismic displacement of more

141 than $1 \mathrm{~cm}$ at seafloor sites (sources are shown in Figure 1), applying the method of

142 Okada (1992). We used the Centroid Moment Tensor (CMT) solution catalogue

143 provided by the Japan Meteorological Agency, which are available online 
This is a non-peer reviewed preprint submitted to EarthArXiv.

144 (https://www.data.jma.go.jp/svd/eqev/data/bulletin/index_e.html). We then smoothen

145 the time series of postseismic displacements, $x(t)$, where $t$ denotes the time after the

146 event, by fitting with a function which are modified from the fitting curve of Tobita et

147 al. (2017), i.e.,

$$
x(t)=x_{0}+v t+\alpha_{1} \log \left(1+\frac{t}{\tau_{1}}\right)+\alpha_{2} \log \left(1+\frac{t}{\tau_{2}}\right)
$$

149 where $x_{0}, v, \alpha_{1}$ and $\alpha_{2}$ are estimation parameters. For the time constants $\tau_{1}$ and

$150 \tau_{2}$, we applied the values of Fujiwara et al. (2021), i.e., $\tau_{1}=2.1176$ day and $\tau_{2}=$

151287.45 day, because the GNSS-A observation frequency is as low as several times per

152 year per site which is insufficient to determine these parameters. Additionally, we

153 approximated the exponential term in their formulation to a linear component, $v t$,

154 because of extremely large time constant found by Fujiwara et al. (2021). It should also

155 be noted that we put $\alpha_{1}=0$ for the TU sites where the observation started in 2013 .

$156 \quad 3$ Results

157 Time series of post- and preseismic seafloor displacements with respect to the

158 Okhotsk plate of NNR-MORVEL56 model (Argus et al., 2011) within a framework of

159 the International Terrestrial Reference Frame 2014 (Altamimi et al., 2016; 2017) are 
This is a non-peer reviewed preprint submitted to EarthArXiv.

160 shown in Figures 2 and S2 (Additional file 1), respectively. The values of the

161 displacement, without corrections for aftershocks, are available at Zenodo (Watanabe et

162 al., 2021c). To discuss the motion changes over several years, we extracted 3-year

163 cumulative movements from the fitted curves for the periods of Apr. 2011 - Apr. 2014,

164 Apr. 2014 - Apr. 2017, and Apr. 2017 - Apr. 2020 (Table 2, Figure 1). For the

165 preseismic period, we only consider the average velocity (Table 2, Figure 1a).

166 The GNSS-A results at the TU sites independently operated by the TU research

167 group (Kido et al., 2015; Honsho et al., 2019) are simultaneously plotted in Figures 2g-

$1682 \mathrm{k}$ for comparison. The offsets in the results between two observation systems, i.e., JCG

169 and TU, were estimated and corrected as follows: We first estimated the linear trend of

170 JCG's results in the period of 2013-2017, and detrended both series. Offsets were

171 calculated from the average of differences in the detrended results for 2013-2017. Text

172 S1 (Additional file 1) describes the validations for data at G17, which has lower

173 positioning precision that the other sites. 
This is a non-peer reviewed preprint submitted to EarthArXiv.

174

175

176

177

178

179

180

181

182

183

184

185

186

187

\section{Discussions}

Based on the temporal changes of seafloor movement (Figure 1), we discuss the expressions of viscoelastic relaxation and afterslip in the northern (off-Kamaishi), central (off-Miyagi/main rupture), and southern (off-Fukushima and off-Choshi) parts of the source region, which are conceptually illustrated in Figure 3.

In previous studies that analyzed the data until 2014 (Watanabe et al., 2014; Sun et al. 2014), landward movements at rates larger than the Pacific plate subduction were detected at the sites located above the main rupture, i.e., KAMS and MYGI (Figure 1b). This was interpreted as the superposition of the effects of viscoelastic relaxation in the asthenosphere beneath the Pacific plate, and the interplate backslip if the interplate coupling was restored (Figure 3b). Crustal deformation in this area was consistent with the quantitative models incorporating the viscoelastic response to the geodetically constrained coseismic input (Sun et al. 2014; Sun and Wang, 2015; Freed et al., 2017;

Wang et al., 2018). The large landward movements at these sites continued with a slight decay over the whole period, as well as at G08, G10, G12, and G14 (Figure 1c). The 
This is a non-peer reviewed preprint submitted to EarthArXiv.

189 decay of landward motion can be explained as the time-dependent viscoelastic

190 deformation (Figure 3b).

191 Little temporal change in the present decade was found in the horizontal

192 movement at MYGW on the downdip edge of the main rupture (Figures $1 \mathrm{~b}-1 \mathrm{~d}$ ). If the

193 interplate coupling in the main rupture had been restored, its landward motion should be

194 canceled by a trench-ward motion driven by viscoelastic relaxation or afterslip to

195 maintain balance for almost 10 years. Although the landward motion cannot be clearly

196 detected, it seems to have been slightly restored after 2017. This might indicate a

197 decrease in the dominance of relaxation processes similar to those in the main rupture

198 area (Figure 3b).

199 At the northern edge of the main rupture, little horizontal displacement was

200 observed until 2014 at KAMN (Figure 1b). Because viscoelastic relaxation is mainly

201 driven by the stress induced in the low-viscosity layer beneath the lithosphere, it tends

202 to cause almost the same movements at KAMN and KAMS which are only $30 \mathrm{~km}$ apart.

203 To explain the velocity contrast at KAMN and KAMS, some postseismic models

204 require afterslip to reach the trench on the northern side of the main rupture to cause a 
This is a non-peer reviewed preprint submitted to EarthArXiv.

205 relative trench-ward motion at KAMN with respect to KAMS (Sun and Wang, 2015;

206 Freed et al., 2017).

After 2014, landward motion significantly accelerated at KAMN and had almost

208 the same velocity at KAMS and MYGI (Figure 1c). With the preseismic velocities

209 (Figure 1a) taken into account, the consistency in the movements at KAMN and KAMS

210 after 2014 indicates that the two sites have been similarly influenced by long-term

211 viscoelastic relaxation. Because the spatial pattern of the viscoelastic deformation has

212 not significantly changed in the present decade, the viscoelastic relaxation is expected to

213 have caused almost the same displacements at these sites before 2014. This supports

214 that the afterslip in the off-Kamaishi region actually caused the relative trench-ward

215 motion of $10 \mathrm{~cm} /$ year in three-year average at KAMN before 2014 to cancel the

216 landward motion driven by the viscoelastic relaxation and interseismic backslip (Figure

217 3b). Furthermore, the temporal evolution of KAMN's movement (Figure 2a) confirms

218 that the afterslip in that region had decayed sufficiently in 3 years. After the decay of

219 the afterslip, the viscoelastic response and interplate coupling became dominant for the 
This is a non-peer reviewed preprint submitted to EarthArXiv.

crustal deformation around KAMN, similar to the case at neighboring GNSS-A sites

221 (Figures 3b).

222

To reproduce the difference in average displacement rate of about $10 \mathrm{~cm} /$ year

223 between KAMN and KAMS before 2014, afterslip in the northern region outside the

224 coseismic rupture with an average displacement rate on the order of meters per year is

225 required (see Additional file 1: Text S2 for detail). However, the slip magnitude

226 depends on the afterslip distribution, which cannot be geodetically constrained. With the

227 tsunami-derived shallow slip in the off-Kamaishi area taken into account, the afterslip

228 would not have reached the trench at $39^{\circ} \mathrm{N}$ (Figure $1 \mathrm{~b}$ ).

229

In contrast to the off-Miyagi region, rapid trench-ward movements were

230 observed at FUKU and CHOS in the southern region $\left(<37.5^{\circ} \mathrm{N}\right)$ especially in the first

231 1-2 years after the Tohoku-oki earthquake (Figures 2e-2f). The trench-ward motion

232 became much smaller after 2013 (Figures 2e-2f). Almost no significant horizontal

233 movement was found at G17, located on the trench side of FUKU, despite the low

234 positioning accuracy due to instrumental malfunction $(<5-6 \mathrm{~cm} /$ year for three-year

235 average displacement rate; see Additional file 1: Text S1 for detail). 
This is a non-peer reviewed preprint submitted to EarthArXiv.

237 the trench-ward motion with rapid decay of 1-2 years, as shown in the most postseismic

238 models (Sun and Wang, 2015; Iinuma et al., 2016; Freed et al., 2017; Agata et al.,

239 2019). Actually, it had been indicated that viscoelastic deformation cannot cause

240 significant motion at FUKU in some finite element models (Sun et al., 2014; Freed et

241 al., 2017), which used the coseismic input based on the geodetic inversion with a single

242 peak beneath FUKU, such as the model by Iinuma et al. (2012) (Figure 1b). Therefore,

243 such models require to reproduce both the horizontal and vertical motion by only the

244 afterslip. It led to the assumption of the strong afterslip in the shallow portion to explain

245 the rapid subsidence observed at FUKU.

246 However, subsidence at FUKU continued at almost a constant rate of about 4

$247 \mathrm{~cm} /$ year, even after 2014 when the trench-ward movement had almost ceased. This

248 result is against the models which try to explain the most parts of both trench-ward

249 motion and subsidence with a shallow afterslip. A single afterslip cannot cause a

250 persistent subsidence without significant trench-ward movement at FUKU and G17,

251 because of the low dip angle of the plate boundary (see Additional file 1: Text S3 for 
This is a non-peer reviewed preprint submitted to EarthArXiv.

252 detail). Therefore, we should assume another input for the viscoelastic deformation

253 rather than the geodetic inversion model to reproduce the persistent subsidence at

254 FUKU.

255

Agata et al. (2019) used a coseismic input derived from an earthquake cycle

256 simulation (Nakata et al., 2016), which incorporates an additional peak of coseismic

257 rupture near the trench at $37^{\circ} \mathrm{N}$. Although the source has not reproduced the coseismic

258 seafloor uplift observed at FUKU (Sato et al., 2011), it can provide a practical exercise.

259 Their viscoelastic finite element model demonstrated sufficient subsidence at FUKU.

260 According to the comparisons of the numerical examples of viscoelastic deformation to

261 the coseismic slip distribution, as illustrated in Figure 6 of Sun and Wang (2015), the

262 hinge line of horizontal deformation and the peak of viscoelastic subsidence were

263 located above the downdip side of the major slip. For this reason, the coseismic slip

264 near the trench caused the subsidence at FUKU in the model of Agata et al. (2019). The

265 tsunami-derived coseismic slip distribution in the off-Fukushima region (Satake et al.,

266 2013) has two peaks in the along-dip direction (Figure 1b). Based on the postseismic 
This is a non-peer reviewed preprint submitted to EarthArXiv.

267

268

269

270

271

272

273 landward motion at G17 (red and yellow arrows in Figure 3b, respectively). However, it

274 cannot be well detected because of low accuracy at G17. The data is consistent for both

275 cases where G17 actually moves toward the land and where the landward motion is

276 canceled or weaken by remaining afterslip. Therefore, the data cannot constrain the

277 degrees of contribution of viscoelastic response or afterslip to slight trench-ward motion

278 at FUKU in 2014-2017.

279

280 CHOS for the first 1-2 years were mainly caused by afterslip in the southern region

281 (purple arrows in Figure 3b). Although we cannot constrain and estimate the spread of

model of Agata et al. (2019), the viscoelastic relaxation driven by the shallower

coseismic slip can cause long-term subsidence at FUKU (red arrows in Figure 3b).

The discussion above suggests that the tsunami-derived shallow coseismic slip

should be adopted in the viscoelastic relaxation model to reasonably explain the

spatiotemporal variation of seafloor deformation. In this case, both the viscoelastic

relaxation and possible interseismic backslip are predicted to simultaneously cause

In any cases, we can consider that the trench-ward movements at FUKU and

southern afterslip region because of low spatial density of geodetic observation site at 
This is a non-peer reviewed preprint submitted to EarthArXiv.

283 that time, annual-scale afterslip was a dominant deformation source in the southern

284 region except for the vertical component at FUKU. Recalling the tsunami-derived

285 rupture distribution at $37^{\circ} \mathrm{N}$, for reproducing the trench-ward motion at FUKU, it might

286 be reasonable to put the afterslip on the fault between the two peaks of the coseismic

287 slip (Figure 1b) rather than putting strong afterslip patches only in far south of FUKU

$288\left(<37^{\circ} \mathrm{N}\right)$ as the forward slip model shown by Agata et al. (2019).

289 Considering that the afterslip occurs on the fault with aseismic frictional

290 property, the assumed afterslip regions on the northern and southern sides of the main

291 rupture are considered to have behaved as barriers to rupture propagation. It is plausible

292 that the shallow tsunamigenic slip in the off-Kamaishi and off-Fukushima areas (Satake

293 et al., 2013) additionally loaded stress on the downdip side and triggered afterslip. The

294 northern afterslip occurred between major earthquakes, i.e., the 1968 Tokachi-oki

295 earthquake $\left(M_{\mathrm{w}} 8.3\right)$, the 1994 offshore Sanriku earthquake $\left(M_{\mathrm{w}} 7.7\right)$ (Nagai et al.,

296 2001), the 1896 Meiji Sanriku tsunami earthquake ( $\left.M_{\mathrm{w}} 8.1\right)$ (Satake et al., 2017), and

297 the 2011 Tohoku-oki earthquake. The gap between major earthquakes is characterized

298 by relatively low seismicity (Mochizuki et al., 2005), including repeating earthquakes 
This is a non-peer reviewed preprint submitted to EarthArXiv.

299 (Uchida and Matsuzawa, 2013; Igarashi, 2020). Slow earthquake activity has been

300 reported in this area (Nishikawa et al., 2019) as well. Although the northern and along-

301 dip extensions cannot be resolved due to the absence of geodetic instruments, these

302 features are consistent with the aseismic frictional property. In the off-Fukushima

303 region, postseismic movements larger than the main slip were observed for the 2008

304 and 2010 Fukushima-ken-oki earthquakes $\left(M_{\mathrm{j}} 6.9\right.$ and $M_{\mathrm{j}} 6.7$, respectively) (Suito et al.,

305 2011). It is possible that the proposed afterslip in the off-Fukushima region following

306 the Tohoku-oki earthquake occurred in a region near the former afterslip.

3075 Conclusions

308

Based on the GNSS-A observations and the above interpretations, the slip

309 behaviors in the northern and southern areas can be summarized as follows. (1)

310 Afterslip occurred in the northern and southern regions outside the main rupture at

311 depths near the hypocenter, which is consistent with the shallower tsunamigenic slip

312 inducing stress on the downdip aseismic faults. It is plausible that these aseismic

313 afterslip regions stopped the north-south rupture propagation. (2) By at least 2014, the

314 afterslip in the off-Kamaishi, off-Fukushima, and off-Choshi regions had almost 
This is a non-peer reviewed preprint submitted to EarthArXiv.

315 decayed, though there is less evidence for off-Fukushima region because of less

316 information for determining the viscoelastic deformation patterns. (3) Shallow

317 tsunamigenic slip in the south was captured by postseismic seafloor geodesy as a

318 subsequent viscoelastic deformation that caused persistent seafloor subsidence.

319 Additionally, the GNSS-A results indicate that the long-term viscoelastic relaxation

320 process is currently in progress and is dominant in the off-Miyagi and off-Kamaishi

321 regions. It also plays an important role in the off-Fukushima region, although its

322 contribution cannot be well resolved. These long-term behaviors should be investigated

323 by continuing and expanding seafloor geodetic observations.

\section{Declarations}

325

326

327

328

329

\section{Ethics approval and consent to participate}

Not applicable

Consent for publication

Not applicable

\section{List of abbreviations}

CMT: Centroid Moment Tensor, GNSS: Global Navigation Satellite 
This is a non-peer reviewed preprint submitted to EarthArXiv.

331

332

333

334

335

336

337

338

339

340

341

342

343

344

345

346
System, GNSS-A: GNSS - acoustic ranging combined seafloor

positioning system, JCG: Japan Coast Guard, TU: Tohoku University

\section{Availability of data and materials}

The dataset generated during this study are available at Zenodo

(Watanabe et al., 2021c). The GNSS-A analysis software "GARPOS

v1.0.0" is available at Zenodo (Watanabe et al., 2021d). The GNSS-A

data is available at Zenodo (Watanabe et al., 2021a; b). The daily

coordinates of terrestrial GNSS sites were provided by the Geospatial

Information Authority of Japan (http://terras.gsi.go.jp) (Nakagawa et al.,

2019). The contours for some earthquakes were obtained from the

website created by N. Uchida

(https://www.aob.gp.tohoku.ac.jp/ uchida/page_3_asp-e.html). The

depths of the upper interface of the subducting Pacific plate were

obtained from the website created by F. Hirose (https://www.mri-

jma.go.jp/Dep/sei/fhirose/plate/en.PlateData.html). The CMT solutions

provided by the Japan Meteorological Agency are available at 
This is a non-peer reviewed preprint submitted to EarthArXiv.

https://www.data.jma.go.jp/svd/eqev/data/bulletin/index_e.html. Some

figures were prepared using Generic Mapping Tools

(https://www.generic-mapping-tools.org/).

\section{Competing interests}

Authors declare that they have no competing interests.

\section{Funding} the University of Tokyo Excellent Young Researcher project (YY).

Software: SW

359

Formal analysis: SW, YN

360

Data curation: SW, YN 
This is a non-peer reviewed preprint submitted to EarthArXiv.

363

364

365

366

367

368

369

370

371

372

373

374

375

376

377

Geophys Res Solid Earth 121:6109-6131. doi:10.1002/2016JB013098

378
Visualization: SW

Writing - original draft: SW

Writing - review \& editing: SW, TI, YN, YY

\section{Acknowledgements}

We would like to thank Motoyuki Kido of the Tohoku University for

allowing us to use their seafloor geodetic instruments, i.e., G08, G10,

G12, G14 and G17. In-situ observations were performed by the survey

vessels operated by the Japan Coast Guard.

\section{References}

Agata R, Barbot SD, Fujita K, Hyodo M, Iinuma T, Nakata R, Ichimura T, Hori T (2019)

Rapid mantle flow with power-law creep explains deformation after the 2011 Tohoku

mega-quake. Nat Commun 10:1385. doi:10.1038/s41467-019-08984-7

Altamimi Z, Rebischung P, Métivier L, Collilieux X (2016) ITRF2014: A new release of the International Terrestrial Reference Frame modeling nonlinear station motions. $J$

Altamimi Z, Métivier L, Rebischung P, Rouby H, Collilieux X (2017) ITRF2014 plate 
This is a non-peer reviewed preprint submitted to EarthArXiv.

379 motion model. Geophys J Int 209:1906-1912. doi: 10.1093/gji/ggx136

380 Argus DF, Gordon RG, DeMets C (2011) Geologically current motion of 56 plates

381 relative to the no-net-rotation reference frame. Geochem Geophys Geosyst, 12:Q11001.

382 doi:10.1029/2011GC003751

383 Freed AM, Hashima A, Becker TW, Okaya DA, Sato H, Hatanaka Y (2017) Resolving

384 depth-dependent subduction zone viscosity and afterslip from postseismic displacements

385 following the 2011 Tohoku-Oki, Japan earthquake. Earth Planet Sci Lett 459:279-290.

386 doi:10.1016/j.eps1.2016.11.040

387 Fujita M, Ishikawa T, Mochizuki M, Sato M, Toyama S, Katayama M, Kawai K,

388 Matsumoto Y, Yabuki T, Asada A Colombo OL (2006) GPS/acoustic seafloor geodetic

389 observation: method of data analysis and its application. Earth Planets Space 58:265-

390 275. doi:10.1186/BF03351923

391 Fujiwara S, Tobita M, Ozawa S (2021) Spatiotemporal Functional Modeling of

392 Postseismic Deformation After the 2011 Tohoku-Oki Earthquake. Res Sq.

393 doi:10.21203/rs.3.rs-423959/v1

394 Fujiwara T, Kodaira S, No T, Kaiho Y, Takahashi N, Kaneda Y (2011) The 2011 Tohoku- 
This is a non-peer reviewed preprint submitted to EarthArXiv.

395 Oki earthquake: displacement reaching the trench axis. Science 334:1240, 396 doi:1240.10.1126/science. 1211554

397 Honsho C, Kido M, Tomita F, Uchida N (2019) Offshore postseismic deformation of the 3982011 Tohoku earthquake revisited: Application of an improved GPS-acoustic positioning 399 method considering horizontal gradient of sound speed structure. J Geophys Res Solid 400 Earth 124:5990-6009. doi:10.1029/2018JB017135

401 Igarashi T (2020) Catalog of small repeating earthquakes for the Japanese Islands. Earth 402 Planets Space 72:73. doi:10.1186/s40623-020-01205-2

403 Iinuma T, Hino R, Kido M, Inazu D, Osada Y, Ito Y, Ohzono M, Tsushima H, Suzuki S, 404 Fujimoto H, Miura S (2012) Coseismic slip distribution of the 2011 off the Pacific Coast 405 of Tohoku Earthquake (M9.0) refined by means of seafloor geodetic data. J Geophys Res 406 117:B07409. doi:10.1029/2012JB009186

407 Iinuma T, Hino R, Uchida N, Nakamura W, Kido M, Osada Y, Miura S (2016) Seafloor 408 observations indicate spatial separation of coseismic and postseismic slips in the 2011 409 Tohoku earthquake. Nat Commun 7:13506. doi:10.1038/ncomms13506

410 Ishikawa T, Yokota Y, Watanabe S, Nakamura Y (2020) History of on-board equipment 
This is a non-peer reviewed preprint submitted to EarthArXiv.

411 improvement for GNSS-A observation with focus on observation frequency. Front Earth

412 Sci 8:150. doi:10.3389/feart.2020.00150

413 Kido M, Fujimoto H, Hino R, Ohta Y, Osada Y, Iinuma T, Azuma R, Wada I, Miura S,

414 Suzuki S, Tomita F, Imano M (2015) Progress in the project for development of

415 GPS/Acoustic technique over the last 4 years. In: Hashimoto M (ed) International

416 Symposium on Geodesy for Earthquake and Natural Hazards (GENAH). Springer, pp 3-

417 10. doi:10.1007/1345_2015_127

418 Kido M, Osada Y, Fujimoto H, Hino R, Ito Y (2011) Trench-normal variation in observed

419 seafloor displacements associated with the 2011 Tohoku-Oki earthquake. Geophys Res

420 Lett 38:L24303. doi:10.1029/2011GL050057

421 Mochizuki K, Nakamura M, Kasahara J, Hino R, Nishino M, Kuwano A, Nakamura Y,

422 Yamada T, Shinohara M, Sato T, Moghaddam PP, Kanazawa T (2005) Intense PP

423 reflection beneath the aseismic forearc slope of the Japan Trench subduction zone and its

424 implication of aseismic slip subduction. $J$ Geophys Res 110:B01302. doi:

$425 \quad 10.1029 / 2003 J B 002892$

426 Nagai, R., Kikuchi, M., Yamanaka, Y. (2001) Comparative study on the source processes 
This is a non-peer reviewed preprint submitted to EarthArXiv.

427 of recurrent large earthquakes in Sanriku-oki Region: The 1968 Tokachi-oki earthquake 428 and the 1994 Sanriku-oki earthquake. Zisin(2), 54, 267-280.

429 doi:10.4294/zisin1948.54.2_267

430 Nakata R, Hori T, Hyodo M, Ariyoshi K (2016) Possible scenarios for occurrence of

$431 \mathrm{M} \sim 7$ interplate earthquakes prior to and following the 2011 Tohoku-Oki earthquake

432 based on numerical simulation. Sci Rep 6:25704. doi:10.1038/srep25704

433 Nakagawa H, Toyofuku T, Kotani K, Miyahara B, Iwashita C, Kawamoto S, Hatanaka Y,

434 Munekane H, Ishimoto M, Yutsudo T, Ishikura N, Sugawara Y (2009) Development and

435 validation of GEONET new analysis strategy (Version 4). J Geographical Survey Inst

$436 \quad 118: 1-8$.

437 Nishikawa T, Matsuzawa T, Ohta K, Uchida N, Nishimura T, Ide S (2019) The slow

438 earthquake spectrum in the Japan Trench illuminated by the S-net seafloor observatories.

439 Science 365:808-813. doi:10.1126/science.aax5618

440 Okada Y (1992) Internal deformation due to shear and tensile faults in a half-space. Bull

441 Seism Soc Am 82:1018-1040

442 Ozawa S, Nishimura T, Munekane H, Suito H, Kobayashi T, Tobita M, Imakiire T (2012) 
This is a non-peer reviewed preprint submitted to EarthArXiv.

443 Preceding, coseismic, and postseismic slips of the 2011 Tohoku earthquake, Japan. $J$

444 Geophys Res 117:B07404. doi:10.1029/2011JB009120

445 Satake K, Fujii Y, Harada T, Namegaya Y (2013) Time and space distribution of coseismic

446 slip of the 2011 Tohoku earthquake as inferred from tsunami waveform data. Bull Seismol

447 Soc Am 103:1473-1492. doi:10.1785/0120120122

448 Satake K, Fujii Y, Yamaki S (2017) Different depths of near-trench slips of the 1896

449 Sanriku and 2011 Tohoku earthquakes. Geosci Lett 4:33. doi:10.1186/s40562-017-0099-

$450 \quad \mathrm{y}$

451 Sato M, Fujita M, Matsumoto Y, Ishikawa T, Saito H, Mochizuki M, Asada A (2013a)

452 Interplate coupling off northeastern Japan before the 2011 Tohoku-oki earthquake,

453 inferred from seafloor geodetic data. $J$ Geophys Res 118:3860-3869.

454 doi:10.1002/jgrb.50275

455 Sato M, Fujita M, Matsumoto Y, Saito H, Ishikawa T, Asakura T (2013b) Improvement

456 of GPS/acoustic seafloor positioning precision through controlling the ship's track line. $J$

457 Geod, 118:1-10. doi:10.1007/s00190-013-0649-9 
This is a non-peer reviewed preprint submitted to EarthArXiv.

458 Sato M, Ishikawa T, Ujihara N, Yoshida S, Fujita M, Mochizuki M, Asada A (2011)

459 Displacement above the hypocenter of the 2011 Tohoku-oki earthquake. Science

$460 \quad 332: 1395$. doi:10.1126/science. 1207401

461 Suito H, Nishimura T, Tobita M, Imakiire T, Ozawa S (2011) Interplate fault slip along

462 the Japan Trench before the occurrence of the 2011 off the Pacific coast of Tohoku

463 Earthquake as inferred from GPS data. Earth Planets Space 63:615-619.

464 doi:10.5047/eps.2011.06.053

465 Sun T, Wang K (2015) Viscoelastic relaxation following subduction earthquakes and its

466 effects on afterslip determination. $J$ Geophys Res 120:1329-1344.

467 doi:10.1002/2014JB011707

468 Sun T, Wang K, Fujiwara T, Kodaira S, He J (2017) Large fault slip peaking at trench in

469 the 2011 Tohoku-oki earthquake. Nat Commun 8:14044. doi:10.1038/ncomms14044

470 Sun T, Wang K, Iinuma T, Hino R, He J, Fujimoto H, Kido M, Osada Y, Miura S, Ohta Y,

$471 \mathrm{Hu}$ Y (2014) Prevalence of viscoelastic relaxation after the 2011 Tohoku-oki earthquake.

$472 \quad$ Nature 514:84-87. doi:10.1038/nature13778

473 Tobita M (2016) Combined logarithmic and exponential function model for fitting 
This is a non-peer reviewed preprint submitted to EarthArXiv.

474 postseismic GNSS time series after 2011 Tohoku-Oki earthquake. Earth Planets Space

475 68:41. doi:10.1186/s40623-016-0422-4

476 Tomita F, Kido M, Ohta Y, Iinuma T, Hino R (2017) Along-trench variation in seafloor

477 displacements after the 2011 Tohoku earthquake. Sci Adv 3(7):e1700113.

478 doi:10.1126/sciadv.1700113

479 Uchida N, Matsuzawa T (2013) Pre- and postseismic slow slip surrounding the 2011

480 Tohoku-oki earthquake rupture. Earth Planet Sci Lett 374:81-91.

481 doi:10.1016/j.epsl.2013.05.021

482 Wang K, Hu Y, He J (2012) Deformation cycles of subduction earthquake in a viscoelastic

483 Earth. Nature 484:327-332. doi:10.1038/nature11032

484 Wang K, Sun T, Brown L, Hino R, Tomita F, Kido M, Iinuma T, Kodaira S, Fujiwara T

485 (2018) Learning from crustal deformation associated with M9 2011 Tohoku-oki

486 earthquake. Geosphere 14:552-571. doi:10.1130/GES01531.1

487 Watanabe S, Ishikawa T, Nakamura Y, Yokota Y (2021a) GNSS-A data obtained at the

488 sites along the Japan Trench before the 2011 Tohoku-oki earthquake (Version 1.0.0).

489 Zenodo. doi:10.5281/zenodo.4528990 
This is a non-peer reviewed preprint submitted to EarthArXiv.

490 Watanabe S, Ishikawa T, Nakamura Y, Yokota Y (2021b) GNSS-A data obtained at the

491 sites along the Japan Trench from March 2011 to June 2020 (Version 1.0.0). Zenodo.

492 doi:10.5281/zenodo.4529008

493 Watanabe S, Ishikawa T, Nakamura Y, Yokota Y (2021c) Time series of seafloor

494 displacement at GNSS-A sites along the Japan Trench: from March 2011 to June 2020

495 and before the 2011 Tohoku-oki earthquake (Version 1.0.0). Zenodo.

496 doi:10.5281/zenodo.4628550

497 Watanabe S, Ishikawa T, Yokota Y, Nakamura Y (2020) GARPOS: Analysis Software for

498 the GNSS-A seafloor positioning with simultaneous estimation of sound speed structure.

499 Front Earth Sci 8:597532. doi:10.3389/feart.2020.597532

500 Watanabe S, Ishikawa T, Yokota Y, Nakamura Y (2021d) GARPOS: Analysis tool for

501 GNSS-Acoustic seafloor positioning (Version 1.0.0). Zenodo.

502 doi:10.5281/zenodo.4522027

503 Watanabe S, Sato M, Fujita M, Ishikawa T, Yokota Y, Ujihara N, Asada A(2014) Evidence

504 of viscoelastic deformation following the 2011 Tohoku-oki earthquake revealed from

505 seafloor geodetic observation. Geophys Res Lett 41:5789-5796. 
This is a non-peer reviewed preprint submitted to EarthArXiv.

506 doi:10.1002/2014GL061134

507 Yamanaka Y, Kikuchi M (2004) Asperity map along the subduction zone in northeastern

508 Japan inferred from regional seismic data. J Geophys Res 109:B07307. doi:

$509 \quad 10.1029 / 2003 J B 002683$

510 
This is a non-peer reviewed preprint submitted to EarthArXiv.

\section{$511 \quad$ Figure legends}

512 Figure 1. Seafloor motion derived from GNSS-A observations. Average horizontal

513 and vertical velocities for (a) pre-seismic period, and three-year cumulative

514 displacements for (b) 2011-2014, (c) 2014-2017, and (d) 2017-2020 are indicated as

515 black arrows and open rectangles, respectively. Terrestrial GNSS velocities or

516 cumulative displacements were extracted from the F3 solution of the GEONET sites

517 (Nakagawa et al., 2009). Onshore velocities during 2007-2011 are shown in (a). Purple

518 patches indicate possible afterslip regions, but there is little or no resolution for the

519 spread. Brown contours and colored tiles indicate geodetically derived (Iinuma et al.,

520 2012) and tsunami-derived (Satake et al., 2013) coseismic slip distributions of the 2011

521 Tohoku-oki earthquake, respectively. Green circles denote repeating earthquakes that

522 occurred in each period (Igarashi, 2020). CMT solutions for the use of displacement

523 correction are shown in each panel. Navy and blue lines indicate 2-m and 4-m slip

524 contours of historical earthquakes in the northern area (Nagai et al., 2001). Green 
This is a non-peer reviewed preprint submitted to EarthArXiv.

525 rectangles indicate patches with a slip of $20 \mathrm{~m}$ for the 1896 tsunami earthquake (Satake

526 et al., 2017).

527 Figure 2. Time series of postseismic seafloor displacement. Displacements with

528 respect to the Okhotsk plate of NNR-MORVEL56 model (Argus et al., 2011) are shown

529 (black circles). Fitted logarithmic curves are shown as the solid lines. The $95 \%$

530 confidence intervals for curve fittings are shown as shaded areas. Results provided by

531 Honsho et al. (2019) for (g)-(k) are indicated as brown squares.

532 Figure 3. Schematic diagram of deformation sources beneath the seafloor. (a) Slips

533 on the plate interface. Purple, red, and orange regions indicate possible afterslip region

534 and geodetically derived (Iinuma et al., 2012) and tsunami-derived (Satake et al., 2013)

535 coseismic slip areas of the 2011 Tohoku-oki earthquake, respectively. Blue circles and

536 bars indicate the locations of GNSS-A sites and their projections to the plate interface,

537 respectively. Black rectangles show the locations for cross sections illustrated in

538 subsequent panels. Note that there is little or no information for the spread of afterslip

539 regions. (b) Cross sections for each region with one of possible qualitative explanations

540 for the contributions of each deformation source to the motion at GNSS-A sites. Black, 
This is a non-peer reviewed preprint submitted to EarthArXiv.

541 red, purple, and yellow arrows indicate the observed motion and components due to

542 viscoelastic relaxation, afterslip, and interplate coupling, respectively.

\section{Table legends}

544 Table 1. Summary of previously proposed postseismic deformation models. Models

545 with (1) referencing the seafloor geodetic data, (2) incorporating the afterslip

546 dislocation models, (3) modeling the subducting cold slab, and (4) calculating the

547 viscoelastic deformation in wider area than a latitude range of $37-39^{\circ} \mathrm{N}$, are shown.

548 Table 2. Displacements with respect to the Okhotsk plate from the fitted curves

549 with $95 \%$ confidence intervals.

550 (a) Average velocity before 2011

551 (b) Three-year cumulative displacement from Apr. 2011 to Apr. 2014.

552 (c) Three-year cumulative displacement from Apr. 2014 to Apr. 2017.

553 (d) Three-year cumulative displacement from Apr. 2017 to Apr. 2020.z

\section{Supplementary Information}

$555 \quad$ Additional file 1

556 Figure S1 shows schematic diagrams of the GNSS-A observation operated by the Japan 
This is a non-peer reviewed preprint submitted to EarthArXiv.

557 Coast Guard. Figures S2 shows the time series of preseismic seafloor displacements with

558 respect to the Okhotsk plate. Text S1 describes the validations for the GNSS-A results

559 obtained at G17, which has lower precision than the other sites. Figure S3 shows the

560 actual track lines during the GNSS-A campaign observations at G17, which is referenced

561 in Text S1. Texts S2 and S3 discuss the validity or invalidity of afterslip contributions to

562 the GNSS-A data in the northern and southern regions, respectively. Figures S4 and S5

563 show the contributions of interplate dislocations to the GNSS-A sites in the northern and

564 southern regions, respectively. Table S1 shows the reference locations of the GNSS-A

565 sites. 
Table 1. Summary of previously proposed postseismic deformation models. Models with (1) referencing the seafloor geodetic data, (2) incorporating the afterslip dislocation models, (3) modeling the subducting cold slab, and (4) calculating the viscoelastic deformation in wider area than a latitude range of $37-39^{\circ} \mathrm{N}$, are shown.

\begin{tabular}{|c|c|c|c|c|}
\hline Reference & Rheology model & $\begin{array}{l}\text { Coseismic input } \\
\text { (source) }\end{array}$ & Afterslip model & $\begin{array}{l}\text { Approx. } \\
\text { period }\end{array}$ \\
\hline $\begin{array}{l}\text { Sun et al. } \\
\text { (2014) }\end{array}$ & Burgers model & $\begin{array}{l}\text { Geodetic inversion } \\
\text { (Iinuma et al. 2012) }\end{array}$ & $\begin{array}{l}\text { Modified from Ozawa et al. } \\
\text { (2012) with trial-and-error }\end{array}$ & 3 year \\
\hline $\begin{array}{l}\text { Sun \& Wang } \\
\text { (2015) }\end{array}$ & \multicolumn{2}{|c|}{ Same model as Sun et al. (2014) } & $\begin{array}{l}\text { Ad hoc shallow patches } \\
\text { added to Sun et al. (2014) }\end{array}$ & 3 year \\
\hline $\begin{array}{l}\text { Wang et al. } \\
(2018)\end{array}$ & \multicolumn{2}{|c|}{ Same model as Sun et al. (2014) } & $\begin{array}{l}\text { Ad hoc afterslip patches } \\
\text { added to Sun \& Wang (2015) }\end{array}$ & 5 years \\
\hline $\begin{array}{l}\text { Iinuma et al. } \\
\text { (2016) }\end{array}$ & \multicolumn{2}{|c|}{ Same model as Sun et al. (2014) } & $\begin{array}{l}\text { Geodetic inversion after } \\
\text { removing viscoelastic effect }\end{array}$ & 0.7 year \\
\hline $\begin{array}{l}\text { Freed et al. } \\
(2017)\end{array}$ & $\begin{array}{l}\text { Maxwell model / } \\
\text { depth-dependent }\end{array}$ & $\begin{array}{l}\text { Geodetic inversion } \\
\text { (self-derived) }\end{array}$ & $\begin{array}{l}\text { Geodetic inversion after } \\
\text { removing viscoelastic effect }\end{array}$ & 3 year \\
\hline $\begin{array}{l}\text { Agata et al. } \\
(2019)\end{array}$ & $\begin{array}{l}\text { Power-law / } \\
\text { thermally activated }\end{array}$ & $\begin{array}{l}\text { Earthquake simulation } \\
\text { (Nakata et al., 2016) }\end{array}$ & $\begin{array}{l}\text { Forward calculation based on } \\
\text { rate- \& state-dependent friction }\end{array}$ & 2.8 year \\
\hline
\end{tabular}


Table 2. Displacements with respect to the Okhotsk plate from the fitted curves with $95 \%$ confidence intervals.

(a) Average velocity before 2011

\begin{tabular}{|l|r|r|r|r|r|r|r|}
\hline \multirow{2}{*}{ Site } & \multicolumn{2}{|c|}{ Displacement (cm/year) } & \multicolumn{2}{|c|}{ Variance-covariance ((cm/year) $\left.)^{\mathbf{2}}\right)$} \\
\cline { 2 - 7 } & E-ward & N-ward & U-ward & V(E,E) & V(E,N) & V(N,N) & V(U,U) \\
\hline KAMN & -3.5 & 0.4 & 0.1 & 0.40 & 0.12 & 0.67 & 2.61 \\
\hline KAMS & -2.4 & -1.8 & 0.7 & 2.29 & -1.01 & 1.71 & 2.10 \\
\hline MYGI & -4.1 & 2.4 & -2.0 & 0.24 & -0.03 & 0.50 & 0.93 \\
\hline MYGW & -4.5 & 1.2 & -0.2 & 0.22 & -0.19 & 0.23 & 2.06 \\
\hline FUKU & -1.8 & -1.3 & -2.0 & 0.30 & 0.17 & 1.15 & 3.15 \\
\hline
\end{tabular}

(b) Three-year cumulative displacement from Apr. 2011 to Apr. 2014.

\begin{tabular}{|l|r|r|r|r|r|r|r|}
\hline \multirow{2}{*}{ Site } & \multicolumn{2}{|c|}{ Displacement (cm) } & \multicolumn{2}{|c|}{ Variance-covariance (cm $)$} \\
\cline { 2 - 8 } & E-ward & N-ward & U-ward & V(E,E) & V(E,N) & V(N,N) & V(U,U) \\
\hline KAMN & -4.0 & 3.6 & -21.5 & 4.76 & 3.98 & -1.45 & 11.24 \\
\hline KAMS & -32.6 & 14.9 & -16.1 & 18.22 & 12.28 & -6.08 & 16.05 \\
\hline MYGI & -28.2 & 8.4 & -21.4 & 5.35 & 4.99 & 0.46 & 7.34 \\
\hline MYGW & 7.8 & -14.8 & -32.5 & 2.73 & 3.11 & 0.57 & 7.29 \\
\hline FUKU & 60.4 & -41.9 & -42.1 & 3.56 & 5.00 & -1.59 & 8.34 \\
\hline CHOS & 59.8 & -26.1 & 5.3 & 7.60 & 24.06 & 3.73 & 27.44 \\
\hline
\end{tabular}


(c) Three-year cumulative displacement from Apr. 2014 to Apr. 2017.

\begin{tabular}{|l|r|r|r|r|r|r|r|}
\hline \multirow{2}{*}{ Site } & \multicolumn{1}{|c|}{ Displacement (cm) } & \multicolumn{1}{r|}{ Variance-covariance $\left.\mathbf{( c m}^{2}\right)$} \\
\cline { 2 - 8 } & E-ward & N-ward & $\mathbf{U}$-ward & $\mathbf{V ( E , E )}$ & $\mathbf{V ( E , N )}$ & $\mathbf{V ( N , N )}$ & $\mathbf{V ( U , U )}$ \\
\hline KAMN & -17.0 & 4.4 & -5.6 & 0.78 & 0.65 & -0.24 & 1.84 \\
\hline KAMS & -22.0 & 6.8 & -7.0 & 2.56 & 1.73 & -0.86 & 2.26 \\
\hline MYGI & -20.1 & 7.6 & -10.6 & 1.22 & 1.14 & 0.11 & 1.68 \\
\hline MYGW & -3.3 & -2.2 & -8.6 & 0.61 & 0.70 & 0.13 & 1.63 \\
\hline FUKU & 5.7 & -6.8 & -15.5 & 0.61 & 0.86 & -0.27 & 1.44 \\
\hline CHOS & 1.5 & -1.0 & 0.3 & 0.61 & 1.92 & 0.30 & 2.19 \\
\hline TU08 & -25.5 & 10.5 & -3.7 & 10.39 & 6.56 & -5.44 & 15.66 \\
\hline TU10 & -28.0 & 13.2 & -4.9 & 6.41 & 19.65 & -1.75 & 17.88 \\
\hline TU12 & -38.7 & 17.1 & -7.0 & 10.36 & 14.54 & -2.31 & 14.64 \\
\hline TU14 & -21.2 & 7.4 & -12.2 & 1.58 & 1.96 & -0.94 & 3.55 \\
\hline TU17 & 6.7 & -10.4 & -0.5 & 23.65 & 9.54 & 2.44 & 57.68 \\
\hline
\end{tabular}

(d) Three-year cumulative displacement from Apr. 2017 to Apr. 2020.

\begin{tabular}{|c|c|c|c|c|c|c|c|}
\hline \multirow{2}{*}{ Site } & \multicolumn{3}{|c|}{ Displacement (cm) } & \multicolumn{4}{|c|}{ Variance-covariance $\left(\mathrm{cm}^{2}\right)$} \\
\hline & E-ward & N-ward & U-ward & $\mathbf{V}(\mathbf{E}, \mathbf{E})$ & $\mathrm{V}(\mathbf{E}, \mathbf{N})$ & $\mathrm{V}(\mathbf{N}, \mathbf{N})$ & $\mathbf{V}(\mathbf{U}, \mathbf{U})$ \\
\hline KAMN & -20.5 & 5.3 & -3.7 & 1.61 & 1.35 & -0.49 & 3.80 \\
\hline KAMS & -22.3 & 8.1 & -6.5 & 4.78 & 3.22 & -1.59 & 4.21 \\
\hline MYGI & -20.7 & 7.4 & -8.8 & 2.49 & 2.32 & 0.21 & 3.42 \\
\hline MYGW & -7.2 & -0.4 & -6.1 & 1.24 & 1.42 & 0.26 & 3.32 \\
\hline FUKU & -0.1 & -1.1 & -12.4 & 1.20 & 1.70 & -0.54 & 2.82 \\
\hline CHOS & -2.2 & 2.0 & -2.0 & 1.00 & 3.15 & 0.49 & 3.60 \\
\hline TU08 & -18.5 & 10.8 & 4.0 & 15.90 & 10.03 & -8.33 & 23.96 \\
\hline TU10 & -26.0 & 17.5 & 0.5 & 13.18 & 40.40 & -3.59 & 36.77 \\
\hline TU12 & -28.4 & 19.3 & 6.2 & 19.49 & 27.35 & -4.34 & 27.54 \\
\hline TU14 & -18.2 & 7.7 & -6.1 & 2.45 & 3.02 & -1.46 & 5.49 \\
\hline TU17 & -3.6 & -4.2 & 15.4 & 46.94 & 18.92 & 4.84 & 114.47 \\
\hline
\end{tabular}


a. Before 2011

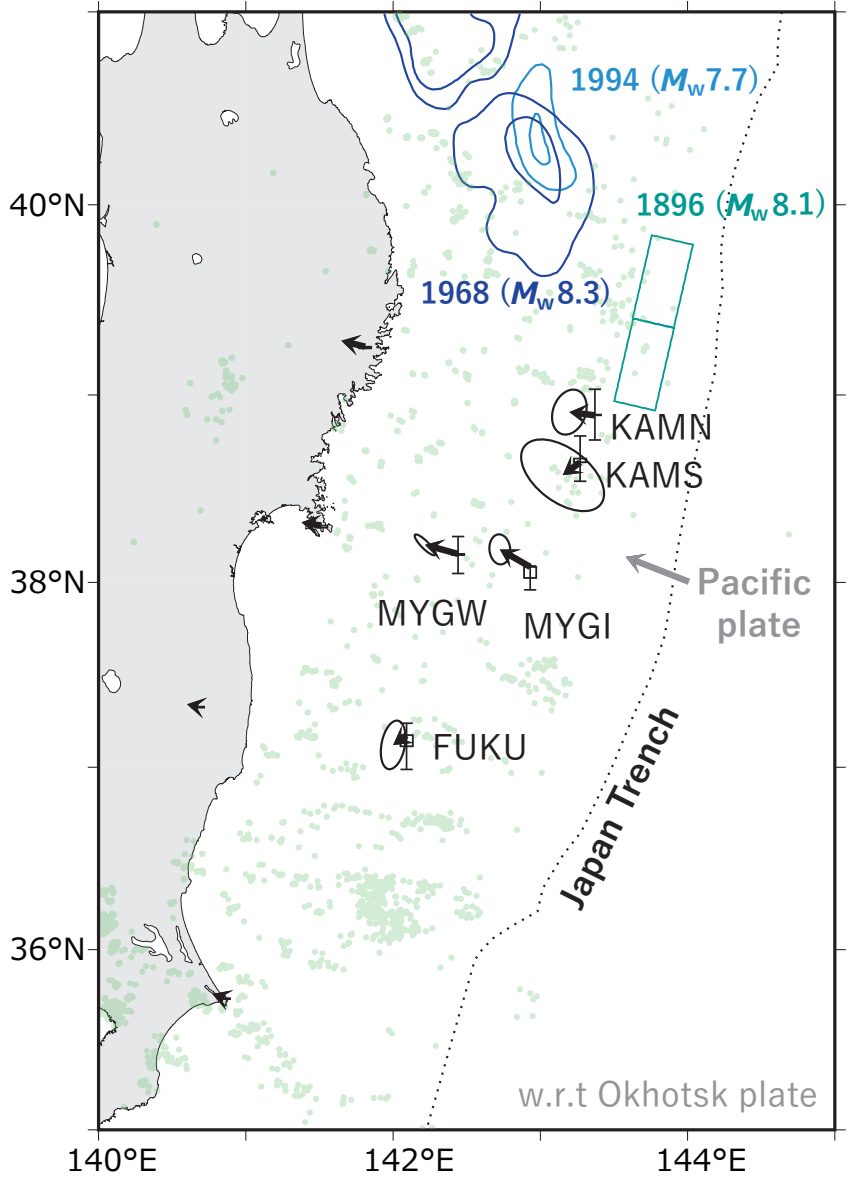

b. Apr. 2011 - Apr. 2014

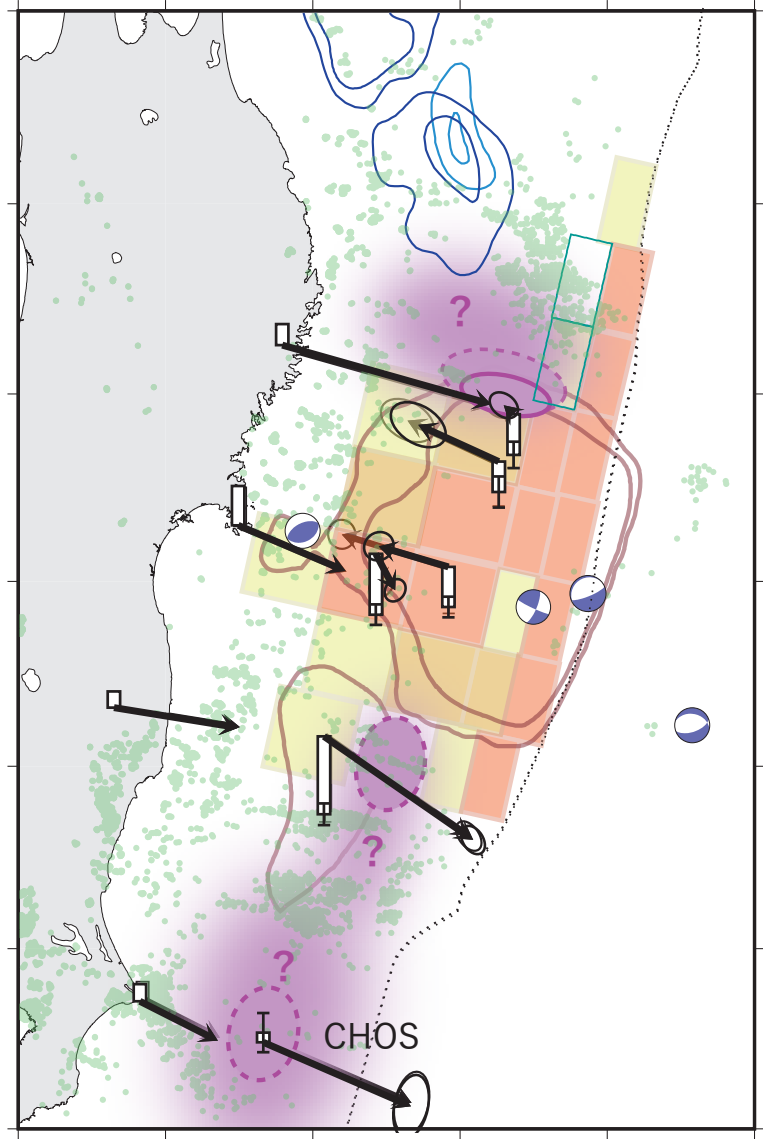

d. Apr. 2017 - Apr. 2020

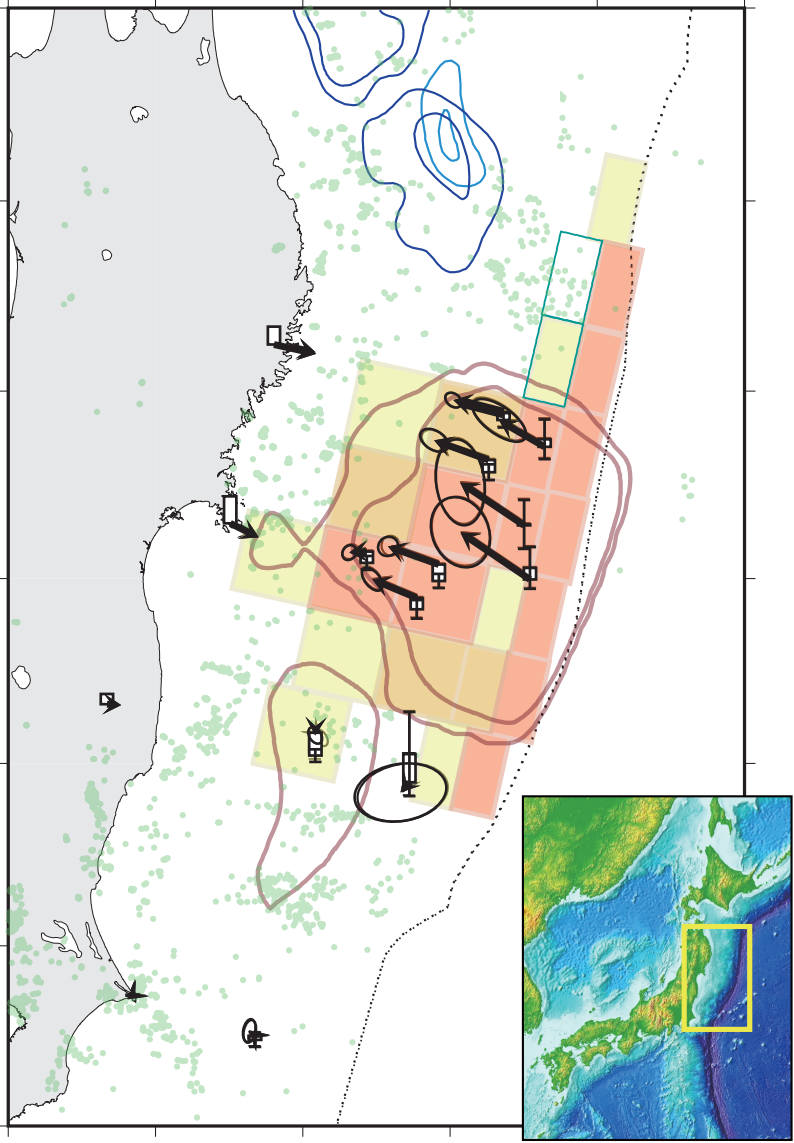

Displacement (obs.)

5 cm/y $95 \% \mathrm{CL}$

$* 15 \mathrm{~cm}$ for (b) - (d)

Possible afterslip

* no resolution for spread
Coseismic slip distributions

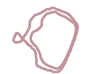

$10 \mathrm{~m} \& 20 \mathrm{~m}$ contours linuma et al. (2012) Geodesy-derived
Tsunami-derived

10 m 15 m 20 m Satake et al. (2013)
20 Nagai et al. (2001)

$\sum \quad \begin{aligned} & \text { Patches of } 20 \mathrm{~m} \\ & \text { Satake et al. (2017) }\end{aligned}$ Igarashi (2020)
Historical earthquakes

(1) $2 \mathrm{~m}$ and $4 \mathrm{~m}$ contours Major aftershock JMA catalogue 
a. KAMN
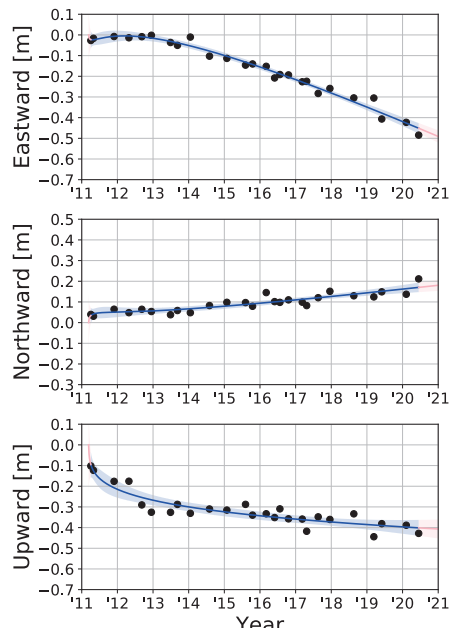

d. MYGW
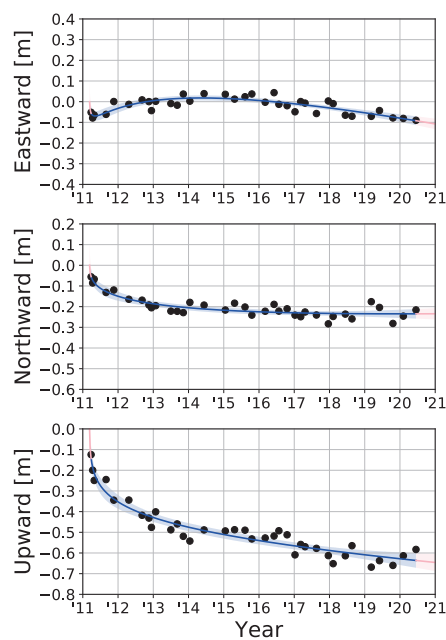

g. G08
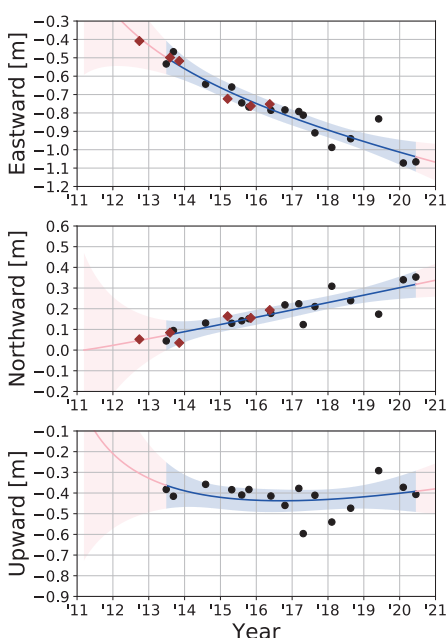

j. G14
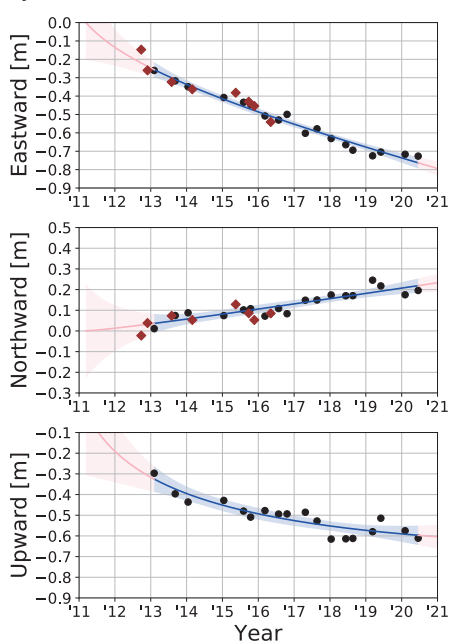

b. KAMS
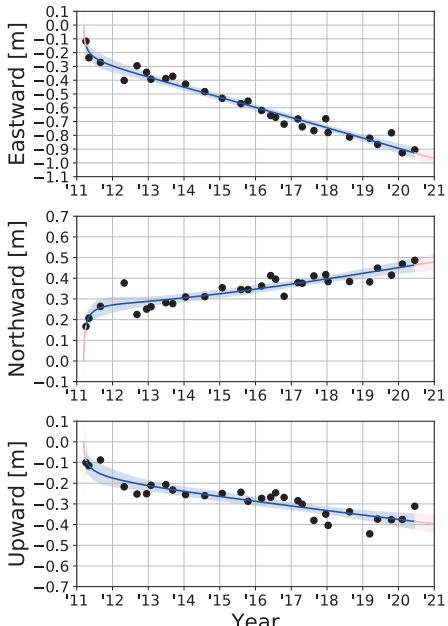

e. FUKU
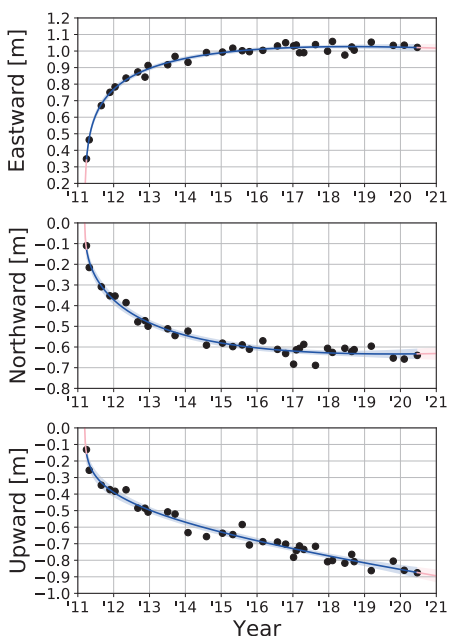

h. G10
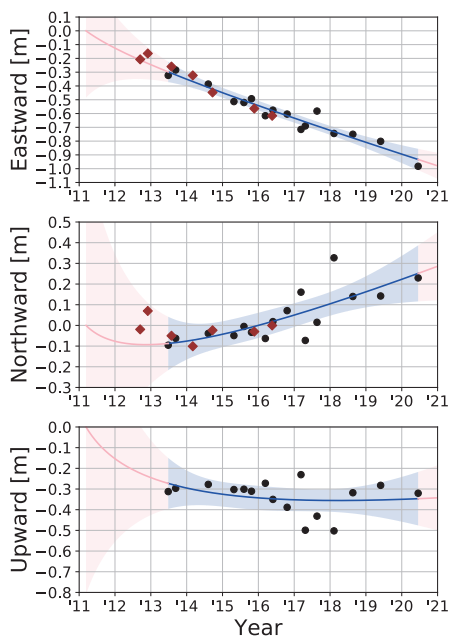

k. G17
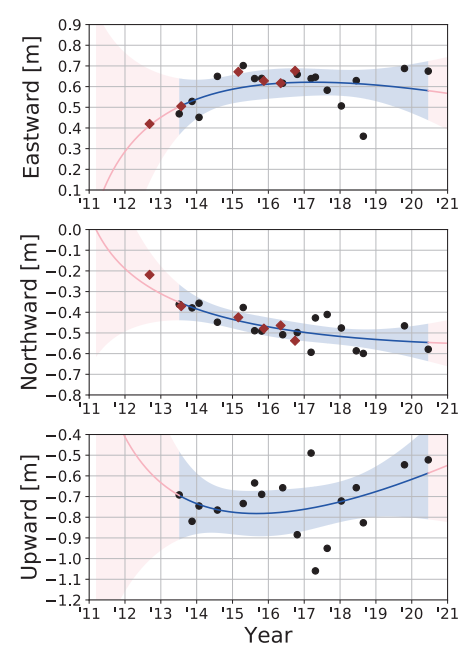

c. MYGI
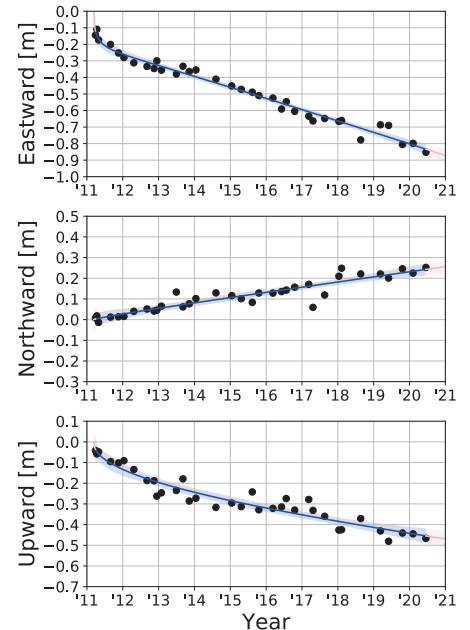

f. CHOS
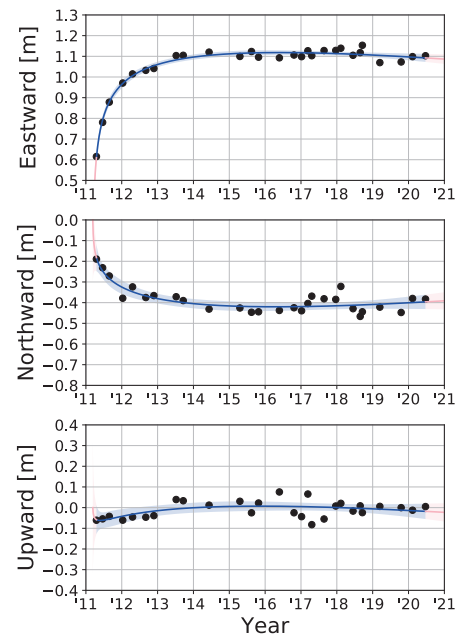

i. G12
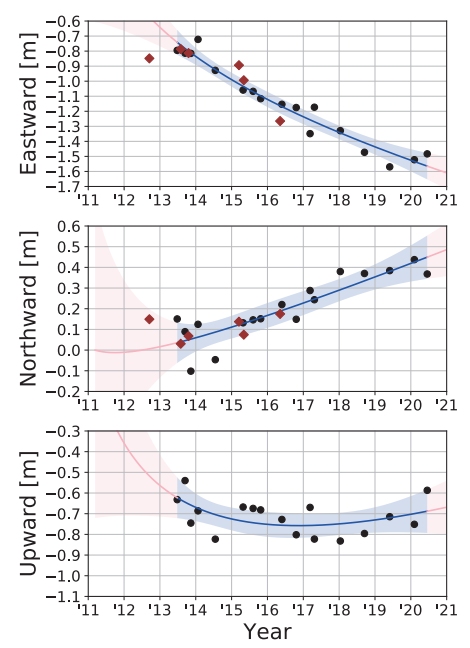$$
\text { . }
$$ 


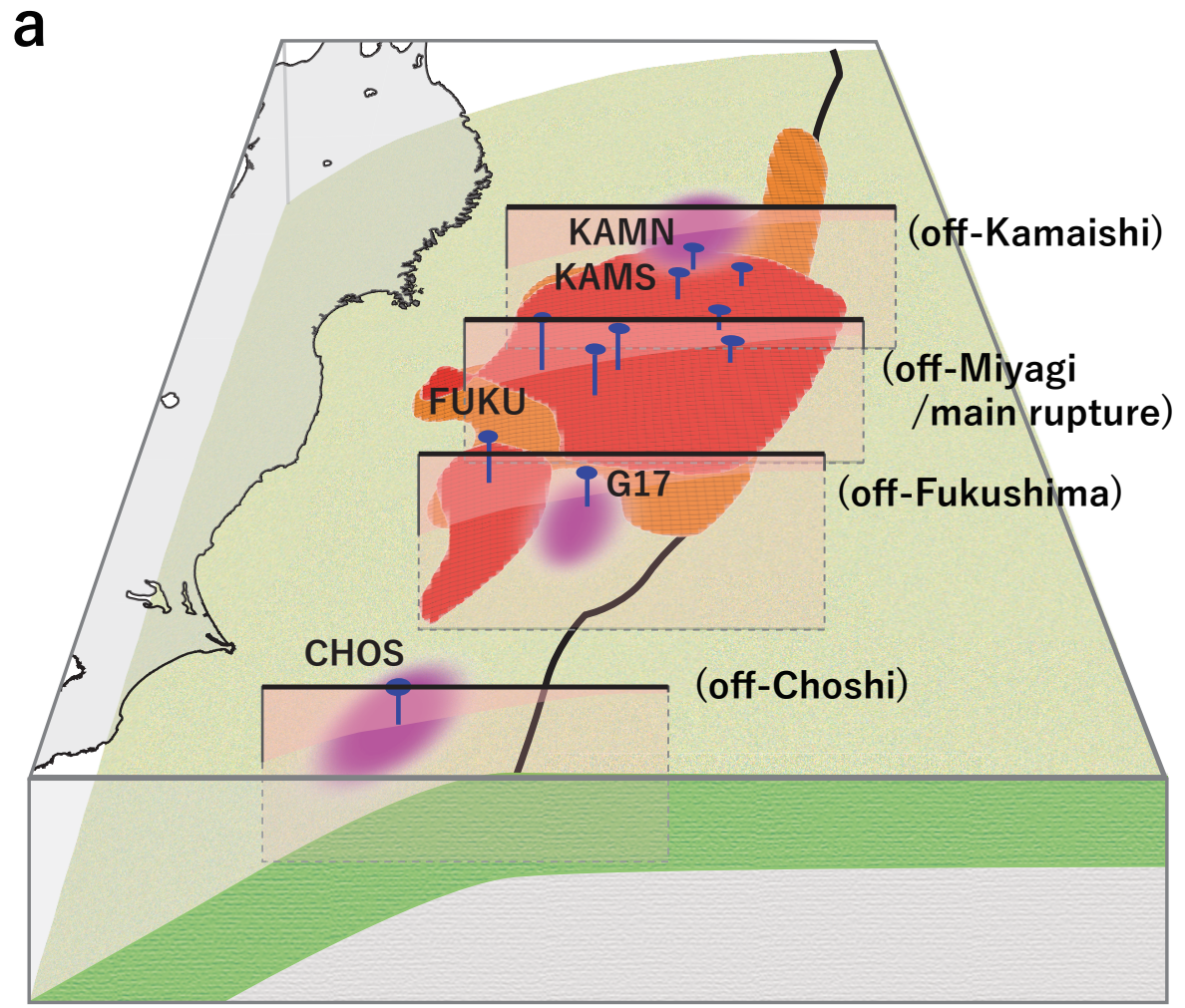

(a) Co- and postseismic slip regions

Possible afterslip

(This study)

*There is little or no information for the spread.

Geodesy-derived coseismic slip

(linuma et al., 2012)

Tsunami-derived coseismic slip

(Satake et al., 2013)

(b) Seafloor motion (qualitative)

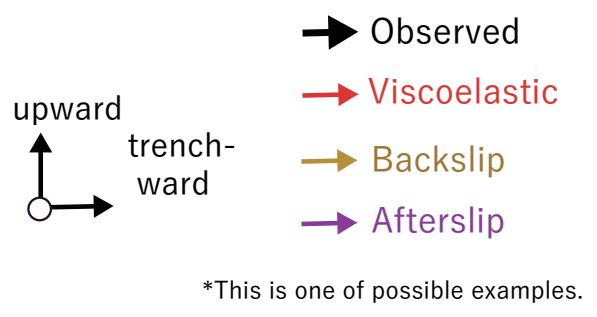

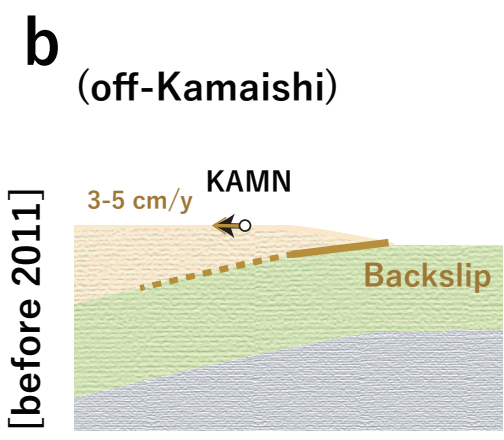

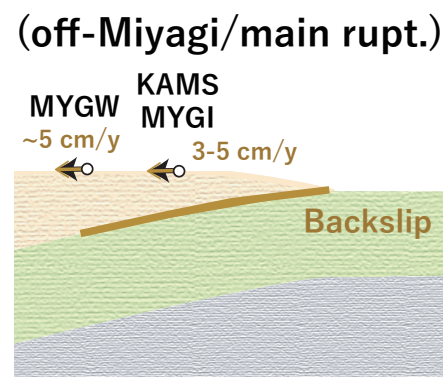

(off-Fukushima)
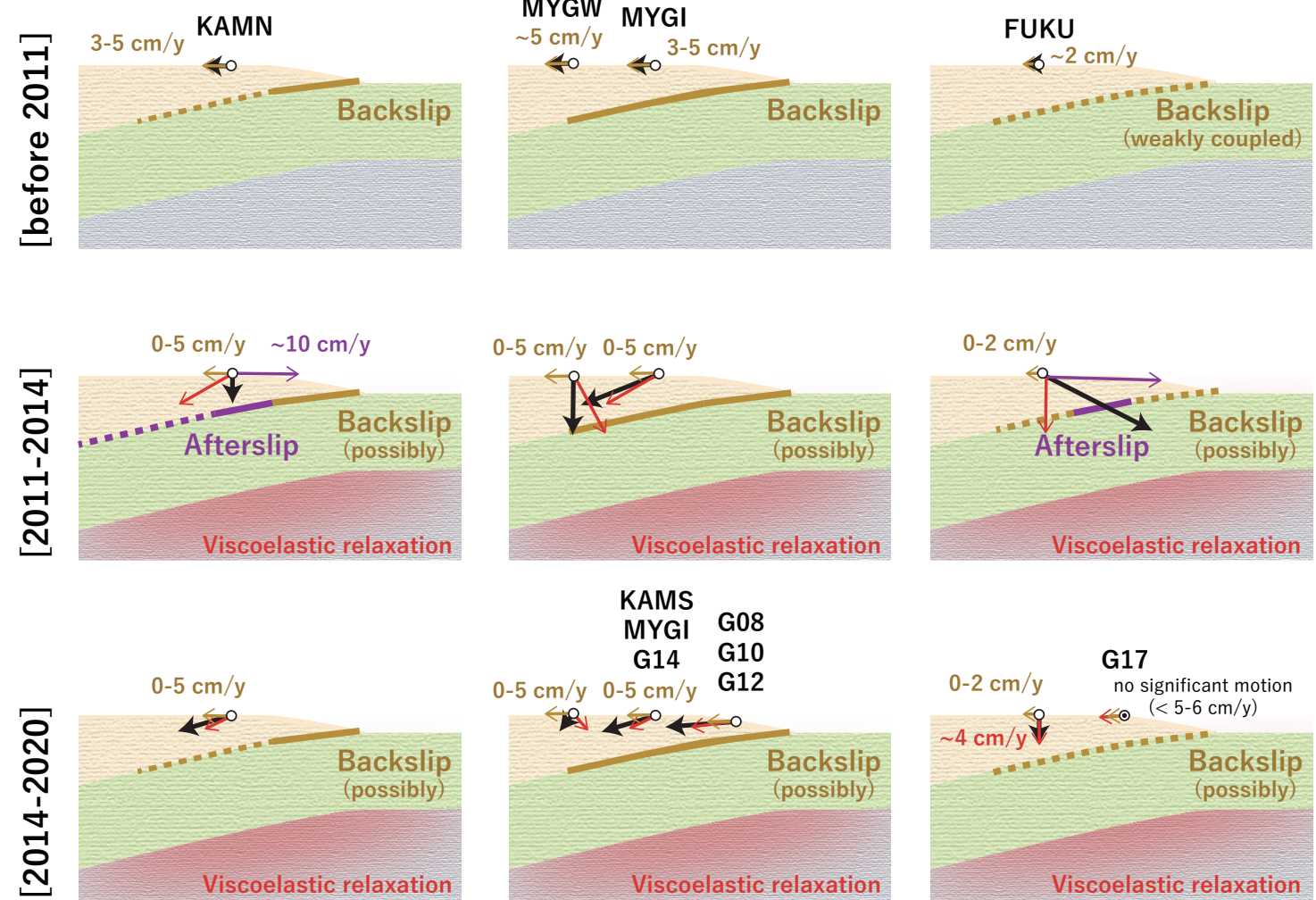

KAMS

MYGI G08

G14 G10
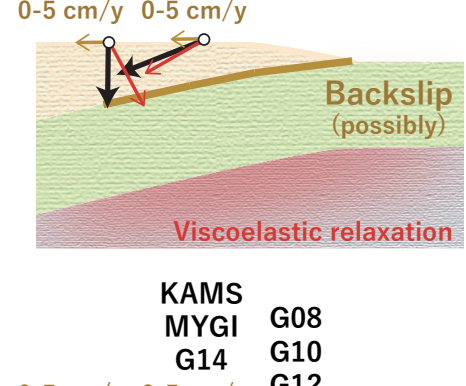

$0-5 \mathrm{~cm} / \mathrm{y} \quad 0-5 \mathrm{~cm} / \mathrm{y} \quad \mathrm{G} 12$

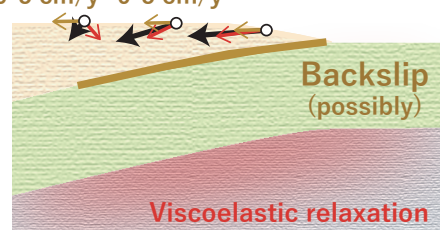

$0-2 \mathrm{~cm} / \mathrm{y}$

(off-Choshi)

No Data

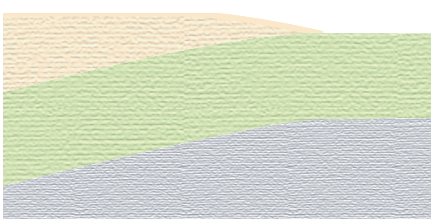

CHOS

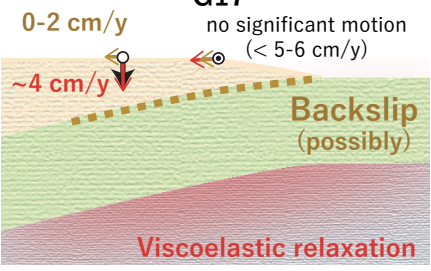

Afterslip

no significant motion <० $(<1-2 \mathrm{~cm} / \mathrm{y})$
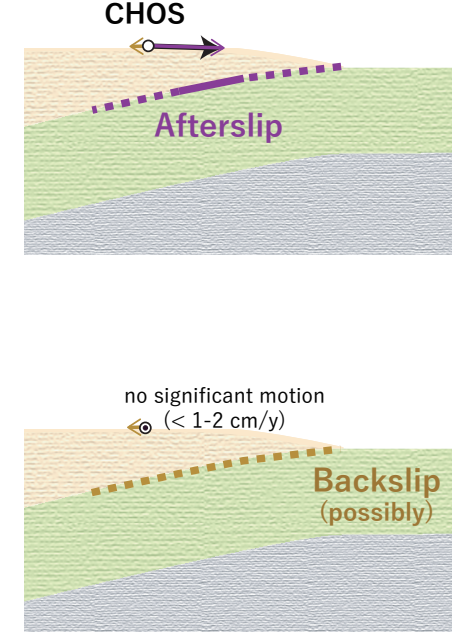


\title{
Co- and postseismic slip behaviors extracted from decadal seafloor geodesy after the 2011 Tohoku-oki earthquake
}

\author{
S. Watanabe ${ }^{1}$, T. Ishikawa ${ }^{1}$, Y. Nakamura ${ }^{1}$, and Y. Yokota ${ }^{2}$ \\ ${ }^{1}$ Hydrographic and Oceanographic Department, Japan Coast Guard \\ ${ }^{2}$ Institute of Industrial Science, University of Tokyo
}

\section{Contents \\ Overview \\ Texts S1 to S3 \\ Figures S1 to S5 \\ Table S1 \\ References}

\section{Overview.}

Figure S1 shows schematic diagrams of the GNSS-A observation operated by the Japan Coast Guard. Figures S2 shows the time series of preseismic seafloor displacements with respect to the Okhotsk plate. Text S1 describes the validations for the GNSS-A results obtained at G17, which has lower precision than the other sites. Figure S3 shows the actual track lines during the GNSS-A campaign observations at G17, which is referenced in Text S1. Texts S2 and S3 discuss the validity or invalidity of afterslip contributions to the GNSS-A data in the northern and southern regions, respectively. Figures S4 and S5 show the contributions of interplate dislocations to the GNSS-A sites in the northern and southern regions, respectively. Table S1 shows the reference locations of the GNSS-A sites.

\section{Text S1.}

The previous study performed by the TU research group (Honsho et al., 2019) showed an average velocity of approximately $10 \mathrm{~cm} /$ year toward the trench at $\mathrm{G} 17$ in a period between 2012 and 2016 and is consistent with our results of the period after 2014, which we are discussing in this study. However, the results at G17 indicated a lower positioning precision compared to the other sites. There should be several reasons as 
follows: Firstly, mirror transponders installed at G17 frequently misrecognized their identification numbers for acoustic ranging, which are necessary to distinguish the transponder that responded to the acoustic signal. Secondly, the on-board systems on some vessels were unable to perform acoustic ranging longer than 10 seconds so that the track line had to be shrunken, until restoration in 2019 (Figure S3). In practice, lack of acoustic data from the outside of the transponder array significantly degrades the positioning accuracy (Nakamura et al., 2021). These errors have also occurred at G12, but G17 seemed to be affected more significantly. The difference between G12 and G17 might be caused by the transponder arrangement or the complexity in the seawater sound speed structure. Although we cannot quantify the positioning accuracy, the results from late 2016 to 2018 tend to contain larger uncertainty than in the other period with wider track line.

\section{Text S2.}

We examine how interplate afterslip can reproduce the relative trench-ward (ESE-ward) seafloor movements of $10 \mathrm{~cm} /$ year at KAMN with respect to KAMS. We calculated the displacements at KAMN and KAMS caused by a dislocation on each $5 \mathrm{~km} \times 5 \mathrm{~km}$ subfault placed at intervals of $0.5^{\circ}$ in latitude and longitude, in an elastic half-space medium (Okada, 1992). For simplification, strike, dip, and rake angles of the subfaults are fixed to $195^{\circ}, 13^{\circ}$, and $90^{\circ}$, respectively. The depths of the subfaults are referenced to Nakajima and Hasegawa (2006). Figure S4 shows the subfaults' contributions to the seafloor movements at KAMN and KAMS. The subfaults located beneath and in the northern side of KAMN significantly contribute to the generation of a relative trench-ward motion at KAMN (green region in Figure S4a). Because the surface displacement from a unit slip on a subfault is $O\left(10^{-3}\right)$, roughly 100 subfaults with a $1 \mathrm{~m} /$ year slip can reproduce the relative velocity of $0.1 \mathrm{~m} /$ year. This is equivalent to a $50 \mathrm{~km} \times 50 \mathrm{~km}$ rectangular fault. There is no resolution for the slip in the white region in Figure S4a, which indicates that our data cannot resolve the afterslip in these regions.

\section{Text S3.}

We examine the coupling of subsidence and trench-ward (ESE-ward) motion at FUKU caused by interplate afterslip. We calculated the displacements at FUKU caused by a dislocation on each $5 \mathrm{~km} \times 5 \mathrm{~km}$ subfault placed at intervals of $0.5^{\circ}$ in latitude and longitude, in an elastic half-space medium (Okada, 1992). For simplification, strike, dip, and rake angles of subfault are fixed to $200^{\circ}, 13^{\circ}$, and $90^{\circ}$, respectively. The depths of the subfaults are referenced to Nakajima and Hasegawa (2006). Figure S5 shows the subfaults' contributions to the seafloor movements at FUKU. Almost all of the subfaults causing subsidence at FUKU (blue region in Figure S5b) simultaneously cause significant trench-ward motion (green region in Figure $\mathrm{S} 5 \mathrm{a}$ ). 
a. Drifting observation (until 2009)
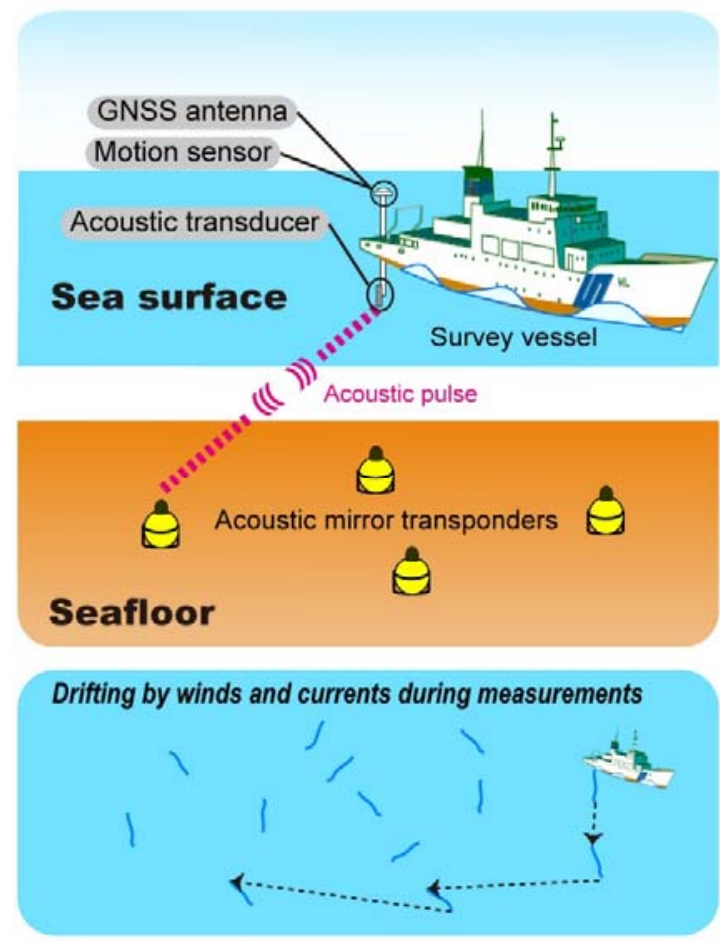

b. Sailing observation (after 2009)
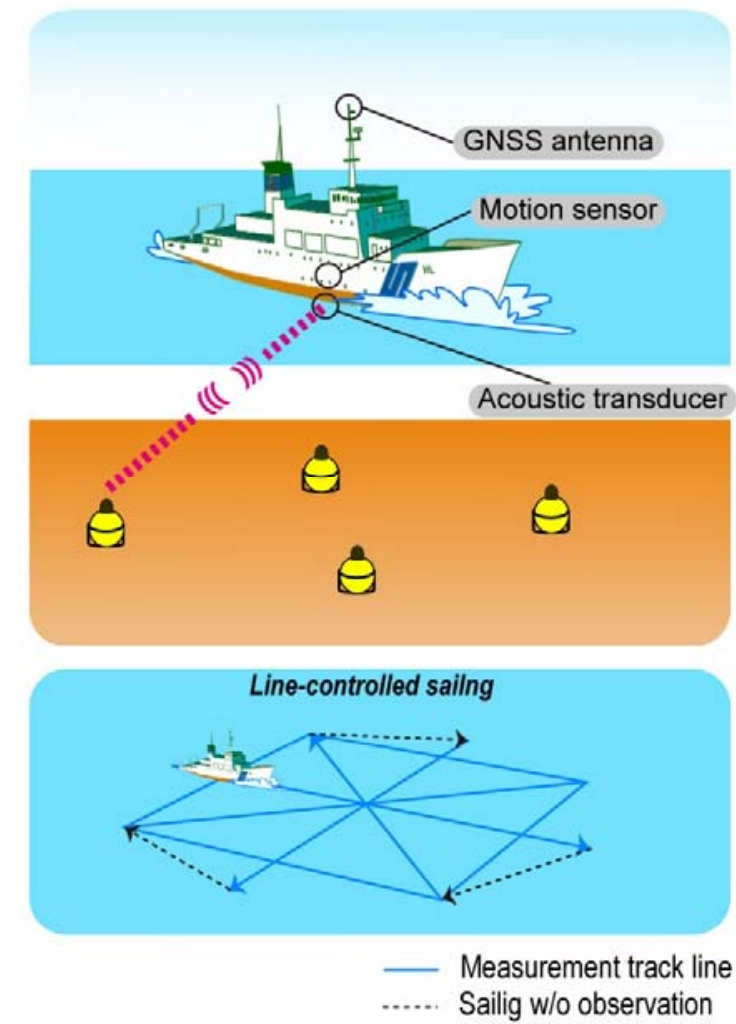

Figure S1. Schematic diagrams of the GNSS-A observation. Observation configurations for (a) drifting and (b) sailing systems are shown. 

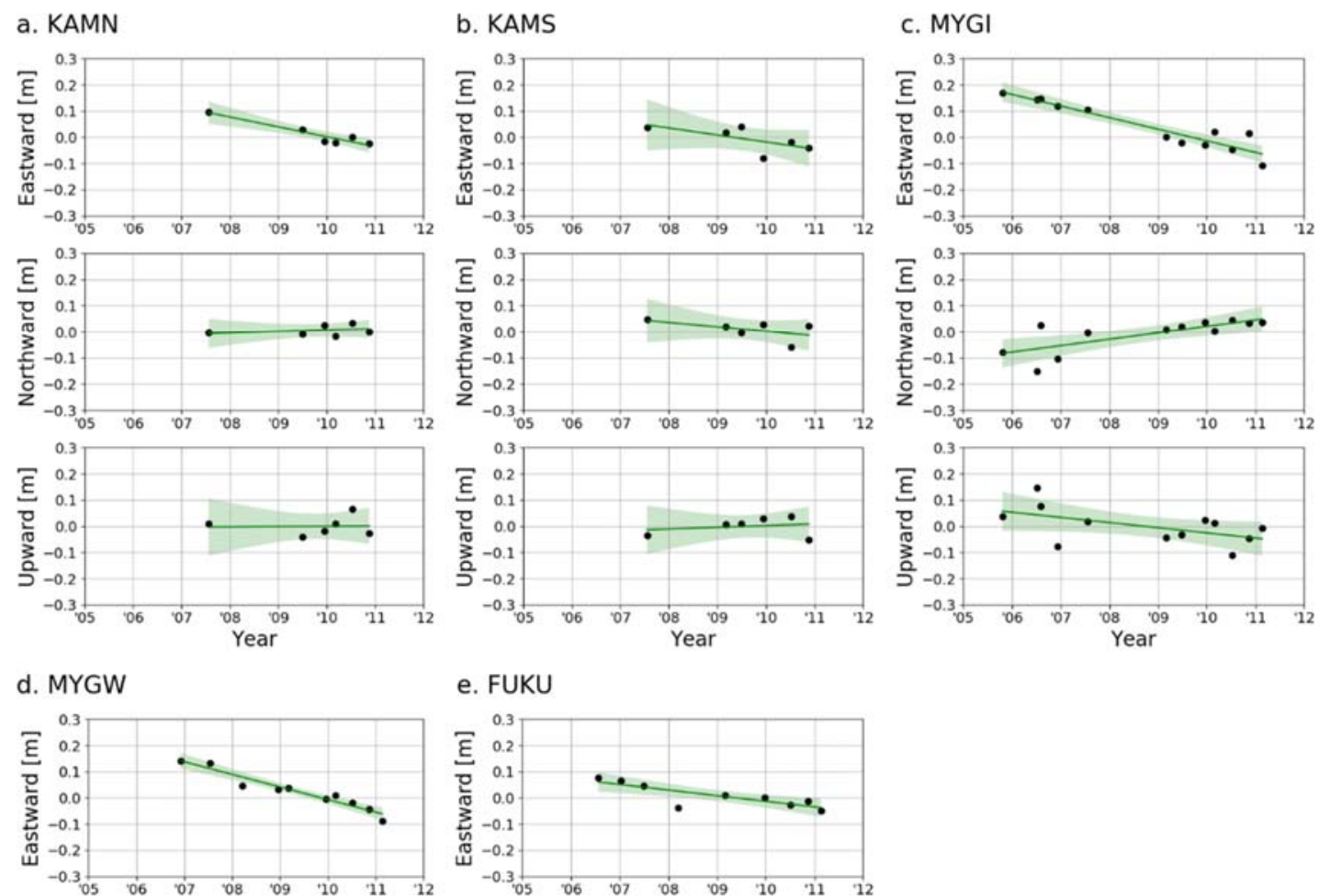

e. FUKU
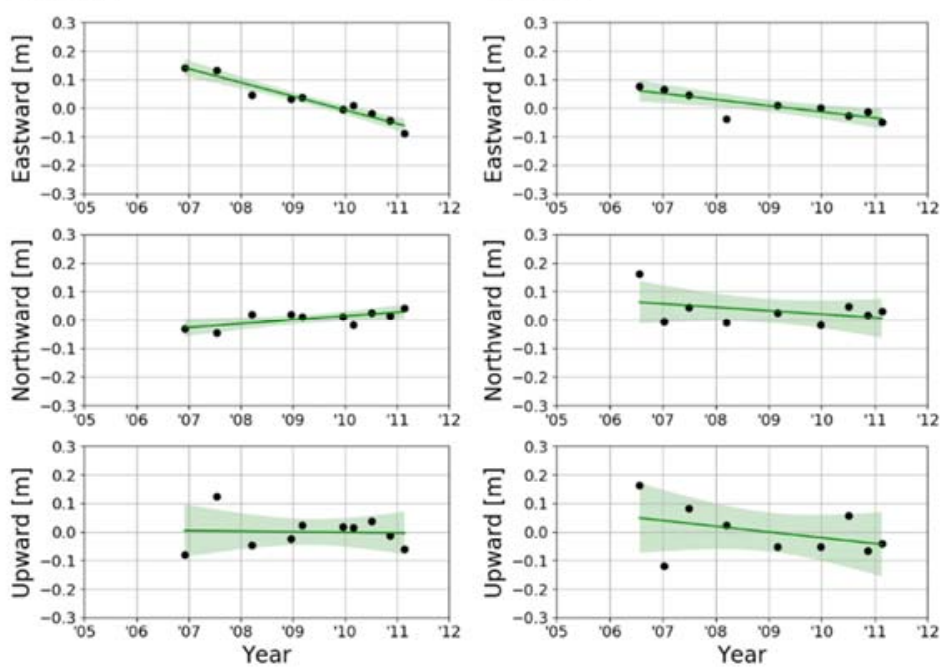

Figure S2. Time series of preseismic seafloor displacement. Displacements with respect to the Okhotsk plate of NNR-MORVEL56 model (Argus et al., 2011) are shown (black circles). Average velocities and their $95 \%$ confidence intervals are shown as solid lines and shaded areas, respectively. 

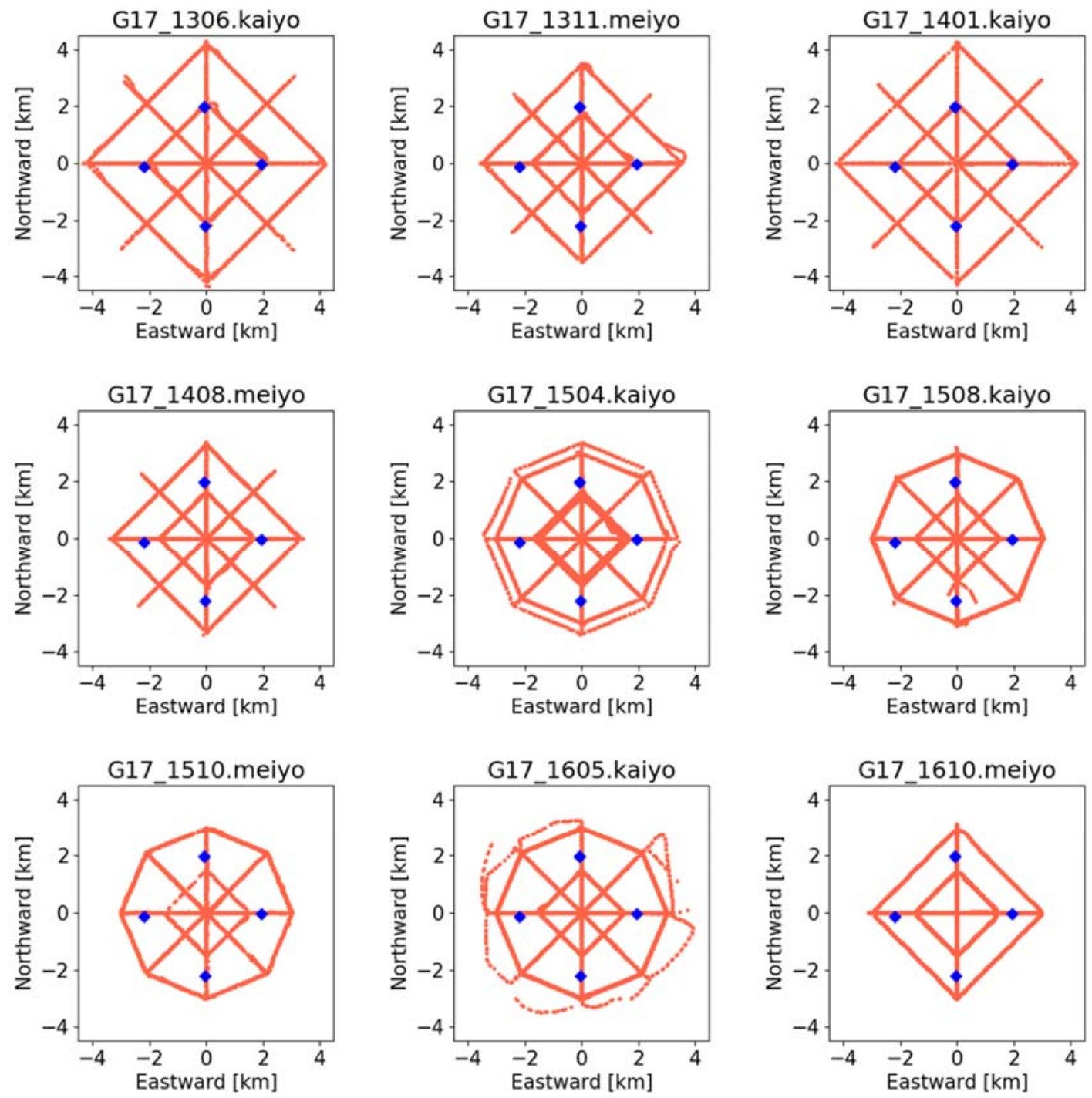

Figure S3. Track lines at G17. Orange dots and blue squares indicate the positions of the surface transducer for each acoustic data and the seafloor transponders, respectively. Titles on each panel shows the 4-digit year-month and the name of the used vessel. 

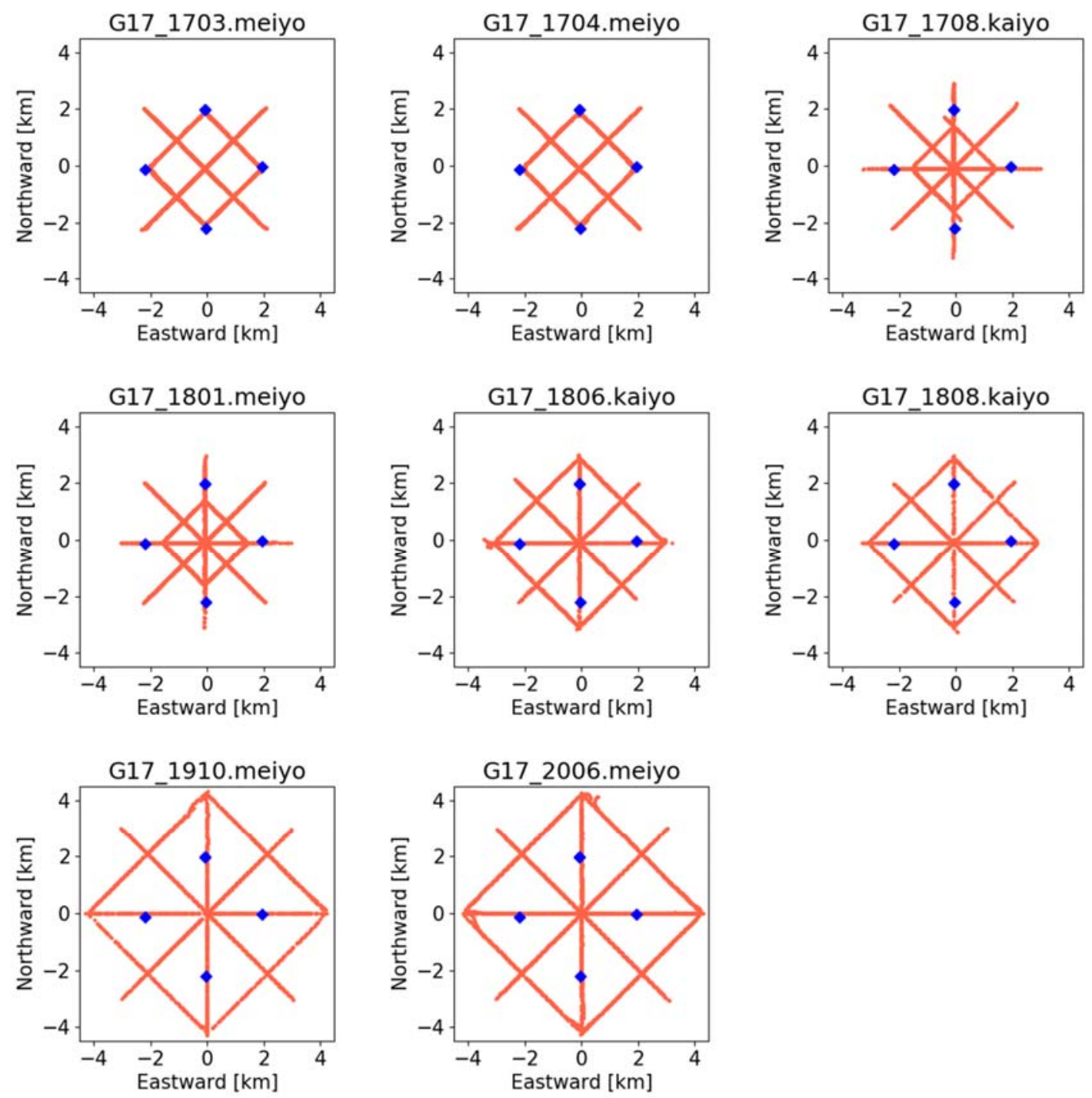

Figure S3. Track lines at G17 (continued). 

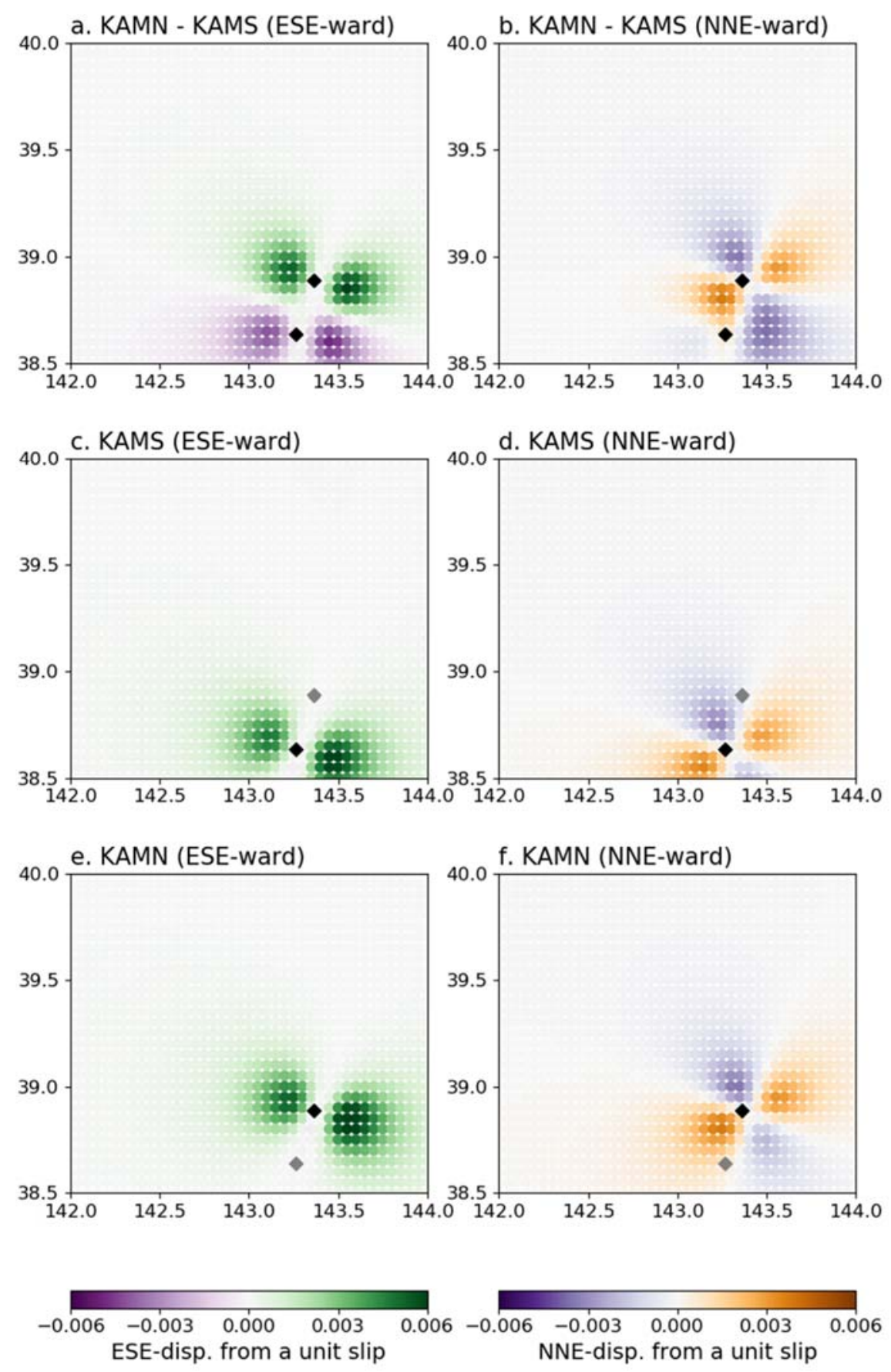

Figure S4. Contributions of the subfaults to (a)-(b) relative horizontal displacement at KAMN relative to KAMS, and (c)-(f) horizontal displacements at KAMN and KAMS.

Strike, dip, and rake angles of the subfaults are fixed to $195^{\circ}, 13^{\circ}$, and $90^{\circ}$, respectively. Black and gray squares indicate the locations of GNSS-A sites (KAMN and KAMS) in concern and not in concern in the panel, respectively. 


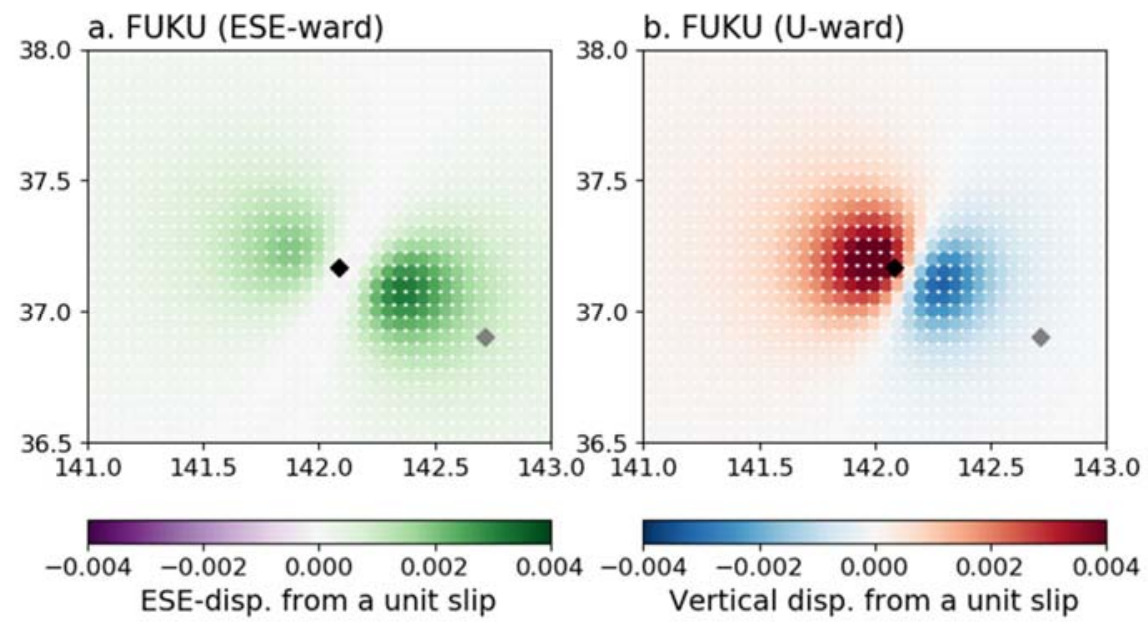

Figure S5. Contributions of the subfaults to (a) ESE-ward and (b) upward displacements at FUKU. Strike, dip, and rake angles of the subfaults are fixed to $200^{\circ}, 13^{\circ}$, and $90^{\circ}$, respectively. Black and gray squares indicate the locations of FUKU and G17, respectively.

Table S1. Reference locations of GNSS-A sites.

\begin{tabular}{ccc}
\hline Site & Longitude $\left({ }^{\circ} \mathrm{E}\right)$ & Latitude $\left({ }^{\circ} \mathrm{N}\right)$ \\
\hline KAMN & 143.363 & 38.886 \\
KAMS & 143.263 & 38.636 \\
MYGI & 142.917 & 38.083 \\
MYGW & 142.433 & 38.150 \\
FUKU & 142.083 & 37.167 \\
CHOS & 141.669 & 35.503 \\
G08 & 143.643 & 38.720 \\
G10 & 143.483 & 38.300 \\
G12 & 143.533 & 38.020 \\
G14 & 142.775 & 37.892 \\
G17 & 142.717 & 36.900 \\
\hline
\end{tabular}




\section{References for this file}

Argus DF, Gordon RG, DeMets C (2011) Geologically current motion of 56 plates relative to the no-net-rotation reference frame. Geochem Geophys Geosyst, 12:Q11001. doi:10.1029/2011GC003751

Honsho C, Kido M, Tomita F, Uchida N (2019) Offshore postseismic deformation of the 2011 Tohoku earthquake revisited: Application of an improved GPS-acoustic positioning method considering horizontal gradient of sound speed structure. J Geophys Res Solid Earth 124:5990-6009. doi:10.1029/2018JB017135

Nakajima J, Hasegawa A (2006) Anomalous low-velocity zone and linear alignment of seismicity along it in the subducted Pacific slab beneath Kanto, Japan: Reactivation of subducted fracture zone?. Geophys Res Lett 33:L16309. doi:10.1029/2006GL026773

Nakamura Y, Yokota Y, Ishikawa T, Watanabe S (2021) Optimal transponder array and survey line configurations for GNSS-A observation evaluated by numerical simulation. Front Earth Sci 9:600993. doi:10.3389/feart.2021.600993

Okada Y (1992) Internal deformation due to shear and tensile faults in a half-space. Bull Seism Soc Am 82:1018-1040 